\title{
New Definitions of Economic Cross-Efficiency
}

\author{
Juan Aparicioa, ${ }^{a}$ and José L. Zofíob \\ a Center for Operations Research (CIO), Universidad Miguel Hernández de Elche, E-03202 Elche \\ (Alicante), Spain. \\ b Department of Economics, Universidad Autónoma de Madrid, E-28049 Madrid, Spain. \\ Erasmus Research Institute of Management, Erasmus Universiteit, NL-3062PA Rotterdam, The \\ Netherlands.
}

June 14, 2019

\begin{abstract}
Overall efficiency measures were introduced in the literature for evaluating the economic performance of firms when reference prices are available. These references are usually observed market prices. Recently, Aparicio and Zofío (2019) have shown that the result of applying cross-efficiency methods (Sexton et al., 1986), yielding an aggregate multilateral index that compares the technical performance of firms using the shadow prices of competitors, can be precisely reinterpreted as a measure of economic efficiency. They termed the new approach 'economic cross-efficiency'. However, these authors restrict their analysis to the basic definitions corresponding to the Farrell (1957) and Nerlove (1965) approaches, i.e., based on the duality between the cost function and the input distance function and between the profit function and the directional distance function, respectively. Here we complete their proposal by introducing new economic cross-efficiency measures related to other popular approaches for measuring economic performance. Specifically those based on the duality between the profitability (maximum revenue to cost) and the generalized (hyperbolic) distance function, and between the profit function and either the weighted additive or the Hölder distance function. Additionally, we introduce panel data extensions related to the so-called cost Malmquist index and the profit Luenberger indicator. Finally, we illustrate the models resorting to Data Envelopment Analysis techniques - from which shadow prices are obtained, and considering a banking industry dataset previously used in the cross-efficiency literature.
\end{abstract}

Keywords: Data Envelopment Analysis, Overall efficiency, Cross-efficiency.

\footnotetext{
* An updated and corrected version of this contribution is published as chapter 2 of the book Advances in Efficiency and Productivity II, edited by Juan Aparicio, C.A. Knox Lovell, Jesús T. Pastor and Joe Zhu, and published in Springer Nature's International Series in Operations Research \& Management Science, 2020. Corresponding author: J. Aparicio. Voice: +34 966658517; fax: +34 966658715, e-mail: j.aparicio@umh.es.
} 


\section{Introduction}

In a recent contribution, Aparicio and Zofío (2019) link the notions of overall economic efficiency and cross-efficiency by introducing the concept of economic cross-efficiency. Overall economic efficiency compares optimal and actual economic performance. From a cost perspective and following Farrell (1957), cost efficiency is the ratio of minimum to actual (observed) cost, conditional on a certain quantity of output and input prices. From a profit perspective, Chambers et al. (1998) define the so-called Nerlovian inefficiency as the normalized difference between maximum profit and actual (observed) profit, conditional on both output and input prices.

Cost and profit efficiencies can in turn be decomposed into technical and allocative efficiencies by resorting to duality theory. In the former case, it can be shown that Shephard input distance function is dual to the cost function and, for any reference prices, cost efficiency is always smaller or equal to the value of the input distance function (Färe and Primont, 1995). Consequently, as the distance function can be regarded as a measure of technical efficiency, whatever (residual) difference may exist between the two can be attributed to allocative efficiency. Likewise, in the case of profit inefficiency, Chambers et al. (1998) show that the directional distance function introduced by Luenberger (1992) is dual to the profit function and, for any reference prices, (normalized) maximum profit minus observed profit is always greater than or equal to the directional distance function. Again, since the directional distance function can be regarded a measure of technical inefficiency, any difference corresponds to allocative inefficiency.

In this evaluation framework of economic performance, the reference output and input prices play a key role. In applied studies, the use of market prices allows studying the economic performance of firms empirically. However, in the duality approach just summarized above, reference prices correspond to those shadow prices that equate the supporting economic functions (cost and profit functions) to their duals (input or directional distance functions). Yet there are many other alternative reference prices, such as those that are assigned to each particular observation when calculating the input and directional distance functions in empirical studies. An example are the optimal weights that are obtained when solving the 'multiplier' formulations of Data Envelopment Analysis (DEA) programs that, approximating the production technology, yield the values of the technical efficiencies.

This set of weights can be used to cross-evaluate the technical performance of a particular observation with respect to its counterparts. I.e., rather than using its own 
weights, the technical efficiency of an observation can be re-evaluated using the weights corresponding to other units. ${ }^{1}$ This constitutes the basis of the cross-efficiency methods initiated by Sexton et al. (1986). Taking the mean of all bilateral cross-evaluations using the vector of all (individual) optimal weights results in the cross-efficiency measure. Aparicio and Zofío (2019) realized that if these weights were brought into the duality analysis underlying economic efficiency, by considering them as specific shadow prices, the cross-efficiency measure can be consistently reinterpreted as a measure of economic efficiency and, consequently, could be further decomposed into technical and allocative efficiencies.

In particular, and under the customary assumption of input homotheticity (see Aparicio and Zofío, 2019), cross-efficiency analysis based on the shadow prices obtained when calculating the input distance function results in the definition of the Farrell cost cross-efficiency. Likewise, it is possible to define the Nerlovian profit cross-inefficiency considering the vector of optimal shadow prices obtained when calculating the directional distance function. One fundamental advantage of the new approach based on shadow prices is that these measures are well defined under the assumption of variable returns to scale; i.e., they always range between zero and one, in contrast to conventional crossefficiency methods that may result in negative values. This drawback of the crossefficiency methodology is addressed by Lim and Zhu (2015), who devise an ad-hoc method to solve it, based on the translation of the data. The proposal by Aparicio and Zofío (2019) also takes care of the anomaly effortlessly, while opening a new research path that connects the economic efficiency and cross-efficiency literatures.

This chapter follows-up this new avenue of research by extending the economic cross-efficiency model to a number of multiplicative and additive definitions of economic behavior and their associated technological duals. From an economic perspective this is quite relevant since rather than minimizing cost or maximizing profit, and due to market, managerial or technological constraints, firms may be interested, for example, in maximizing revenue or maximizing profitability. As the economic goal is different, the underlying duality that allows a consistent measurement of economic cross-efficiency is different. For example, for the revenue function, the dual representation of the technology is the output distance function (Shephard, 1953), while for the profitability function it is the generalized distance function (Zofío and Prieto, 2006). Moreover, since the generalized distance function nests the input and output distance functions as particular

\footnotetext{
1 This cross-efficiency evaluation with respect to alternative peers results in smaller technical efficiency scores, because DEA searches for the most favorable weights when performing own evaluations.
} 
cases (as well as the hyperbolic distance function), we can relate the cost, revenue and profitability cross-efficiency models. Also, since a duality relationship may exist between a given supporting economic function and several distance functions, alternative economic cross-efficiency models may co-exist. We explore this situation for the profit function. Besides the already mentioned model for profit efficiency measurement and its decomposition based on the directional distance function, an alternative evaluation can be performance relying on the weighted additive distance function (Cooper et al., 2011) or the Hölder distance function (Briec and Lesours, 1999). We present these last two models and compare them to the one based on the directional distance function. We remark the results of these models differ because of the alternative normalizing constraints that the duality relationship imposes. Hence researchers and practitioners need to decide first on the economic approach that is relevant for their study: cost, revenue, profit, profitability, and then, among the set of suitable distance functions complying with the required duality conditions, choose the one that better characterizes the production process. Related to the DEA methods that we consider in this chapter to implement the economic cross-efficiency models, it is well-known that the use of radial (multiplicative) distance functions project observations to subsets of the production possibility set that are not Pareto-efficient because non-radial input reductions and output increases may be feasible (i.e., slacks). As for additive distance functions, the use of the weighted additive distance function in a DEA context ensures that efficiency is measured against the strongly efficient subset of the production possibility set, while its directional and Hölder counterparts do not. Thus, the choice of distance function is also critical when interpreting results. For example, in the event that slacks are prevalent, this source of technical inefficiency will be confounded with allocative inefficiency when decomposing profit inefficiency. Of course, other alternative models of economic cross-efficiency could be developed in terms of alternative distance functions. And some of them could even generalize the proposals presented here, such as the profit model based on the loss distance function introduced by Aparicio et al. (2016), which nests all the above additive functions.

Finally, in this chapter we also extend the economic cross-efficiency model to a panel data setting where firms are observed over time. For this we rely on existing models that decompose cost or profit change into productivity indices or indicators based on quantities, i.e., the Malmquist productivity index or Luenberger productivity indicator, and their counterpart price formulations. As the Malmquist index or Luenberger indicator can be further decomposed into efficiency change and technological change components, we can further learn about the sources of cost or profit change. As for the price indices 
and indicators, they can also be decomposed so as to learn about the role played by allocative efficiency. We relate this panel data framework to the cross-efficiency model and, by doing so, introduce the concept of economic cross-efficiency change. In this model the cost-Malmquist and profit-Luenberger definitions proposed by Maniadakis and Thanassoulis (2004) and Juo et al. (2015), using market prices to determine cost change and profit change, are modified following the economic cross-efficiency rationale. that replaces the former by the set of shadow prices corresponding to all observations, which results in a complete evaluation of the economic performance observations over time - to the extent that a complete set of alternative prices is considered.

The chapter is structured as follows. In the next section we introduce the notation and recall the economic cross-efficiency model proposed by Aparicio and Zofío (2019). In the third section we present the duality results that allow us to extend the analytical framework to the notion of profitability cross-efficiency based on the generalized distance function, and how it relates to the partially oriented Farrell cost and revenue crossefficiencies. We also introduce two alternative models of profit cross-efficiency based on the weighted-additive and Hölder distance functions. A first proposal of economic crossinefficiency for panel data models based on the cost-Malmquist index and profitLuenberger indicator is propose in section four. In section five we illustrate the empirical implementation of the existing and new definitions of economic cross-efficiency through Data Envelopment Analysis and using a dataset of bank branches previously used in the literature. Finally, relevant conclusions are drawn in section six, along with future venues of research in this field.

\section{Background}

In this section, we briefly introduce the notion of (standard) cross-efficiency in Data Envelopment Analysis and review the concept of economic cross-efficiency. Let us consider a set of $n$ observations (e.g., firms or decision making units, DMUs) that use $m$ inputs, whose (non-negative) quantities are represented by the vector $X \equiv\left(x_{1}, \ldots, x_{m}\right)$, to produce $s$ outputs, whose (non-negative) quantities are represented by the vector $Y \equiv\left(y_{1}, \ldots, y_{s}\right)$. The set of data is denoted as $\left\{\left(X_{j}, Y_{j}\right), j=1, \ldots, n\right\}$. The technology or production possibility set is defined, in general, as $T=\left\{(X, Y) \in R_{+}^{m+s}: X\right.$ can produce $\left.Y\right\}$. 
Relaying on Data Envelopment Analysis (DEA) techniques, $T$ is approximated as $T_{c}=\left\{(X, Y) \in R_{+}^{m+s}: \sum_{j=1}^{n} \lambda_{j} x_{i j} \leq x_{i}, \forall i, \sum_{j=1}^{n} \lambda_{j} y_{r j} \leq y_{r}, \forall r, \lambda_{j} \geq 0, \forall j\right\}$. This corresponds to a production possibility set characterized by constant returns to scale (CRS). Allowing for variable returns to scale (VRS) results in the following definition: $T_{v}=\left\{(X, Y) \in R_{+}^{m+s}: \sum_{j=1}^{n} \lambda_{j} x_{i j} \leq x_{i}, \forall i, \sum_{j=1}^{n} \lambda_{j} y_{i j} \leq y_{r}, \forall r, \sum_{j=1}^{n} \lambda_{j}=1, \lambda_{j} \geq 0, \forall j\right\}$ - see Banker et al. $(1984) .^{2}$

Let us now introduce the notion of Farrell cross-efficiency.

\subsection{Farrell (cost) cross-efficiency}

In DEA, for firm $k$ the radial input technical efficiency assuming CRS is calculated through the following program:

$$
\begin{aligned}
& \operatorname{ITE}_{c}\left(X_{k}, Y_{k}\right)=\max _{U, V} \frac{\sum_{r=1}^{s} u_{r} y_{r k}}{\sum_{i=1}^{m} v_{i} x_{i k}} \\
& \text { s.t. } \\
& \frac{\sum_{r=1}^{s} u_{r} y_{i j}}{\sum_{i=1}^{m} v_{i} x_{i j}} \leq 1, \quad j=1, \ldots, n, \\
& u_{r} \geq 0, \quad r=1, \ldots, s, \\
& v_{i} \geq 0, \quad i=1, \ldots, m \text {. }
\end{aligned}
$$

Although (1) is a fractional problem, it can be linearized as shown by Charnes et al. (1978). ITE $E_{c}\left(X_{k}, Y_{k}\right)$ ranges between zero and one. Hereinafter, we denote the optimal solution obtained when solving (1) as $\left(V_{k}^{*}, U_{k}^{*}\right)$.

\footnotetext{
${ }^{2}$ Based on these technological characterizations, in what follows we define several measures that allow the decomposition of economic cross-efficiency into technical and allocative components. As it is now well-established in the literature, we rely on the following terminology: We refer to the different factors in which economic cross-efficiency can be decomposed multiplicatively as efficiency measures (e.g., Farrell cost efficiency). Numerically, the greater their value, the more efficient observations are. For these measures one is the upper bound signaling an efficient behavior. Alternatively, we refer to the different terms in which economic crossinefficiency can be decomposed additively as inefficiency measures (e.g., Nerlovian profit inefficiency). Now the greater their numerical value, the greater the inefficiency, with zero being the lower bound associated to an efficient behavior.
} 
Model (1) allows firms to choose their own weights on inputs and outputs in order to maximize the ratio of a weighted (virtual) sum of outputs to a weighted (virtual) sum of inputs. In this manner, the assessed observation is evaluated in the most favorable way and DEA provides a self-evaluation of the observation by using input and output weights that are unit-specific. Unfortunately, this fact hinders obtaining a suitable ranking of firms based on their efficiency score; particularly for efficient observations whose $\operatorname{ITE}_{c}\left(X_{k}, Y_{k}\right)$ $=1$. In contrast to standard DEA, a cross-evaluation strategy is suggested in the literature (Sexton et al., 1986, and Doyle and Green, 1994). In particular, the (bilateral) cross input technical efficiency of unit / with respect to unit $k$ is defined by

$$
\operatorname{CITE}_{c}\left(X_{l}, Y_{l} \mid k\right)=\frac{U_{k}^{*} \cdot Y_{I}}{V_{k}^{*} \cdot X_{l}}=\frac{\sum_{r=1}^{s} u_{r k}^{*} y_{H}}{\sum_{i=1}^{m} v_{i k}^{*} X_{i l}}
$$

$$
\begin{aligned}
& \operatorname{CITE}_{c}\left(X_{l}, Y_{l} \mid k\right) \text { also takes values between zero and one, and satisfies } \\
& \operatorname{CITE}_{c}\left(X_{l}, Y_{l} \mid l\right)=I T E_{c}\left(X_{l}, Y_{l}\right) .^{3}
\end{aligned}
$$

Given the observed $n$ units in the data sample, the traditional literature on crossefficiency postulates the aggregation of the bilateral cross input technical efficiencies of unit $/$ with respect to all units $k, k=1, \ldots, n$, through the arithmetic mean. This results in the definition of the multilateral notion of cross input technical efficiency of unit $l$ :

$$
\operatorname{CITE}_{c}\left(X_{l}, Y_{l}\right)=\frac{1}{n} \sum_{k=1}^{n} \operatorname{CITE}\left(X_{l}, Y_{l} \mid k\right)=\frac{1}{n} \sum_{k=1}^{n} \frac{U_{k}^{*} \cdot Y_{I}}{V_{k}^{*} \cdot X_{I}}=\frac{1}{n} \sum_{k=1}^{n} \frac{\sum_{r=1}^{s} u_{r k}^{*} y_{r l}}{\sum_{i=1}^{m} V_{i k}^{*} X_{i l}}
$$

Before presenting the notion of economic cross-efficiency, we need to briefly recall the main concepts related to the measurement of economic efficiency through frontier analysis, both in multiplicative form (Farrell, 1957) and in additive manner (Chambers et al., 1998). We start considering the Farrell radial paradigm for measuring and decomposing cost efficiency. For the sake of brevity, we state our discussion in the input space, defining the input requirement set $L(Y)$ as the set of non-negative inputs $X \in R_{+}^{m}$ that can produce non-negative output $Y \in R_{+}^{s}$, formally $L(Y)=\left\{X \in R_{+}^{m}:(X, Y) \in T\right\}$, and the isoquant of $L(Y): \operatorname{Isoq} L(Y)=\{X \in L(Y): \varepsilon<1 \Rightarrow \varepsilon X \notin L(Y)\}$. Let us also

\footnotetext{
${ }^{3}$ For a list of relevant properties see Aparicio and Zofío (2019).
} 
denote by $C_{L}(Y, W)$ the minimum cost of producing the output level $Y$ given the input market price vector $W \in R_{++}^{m}: C_{L}(Y, W)=\min \left\{\sum_{i=1}^{m} w_{i} x_{i}: X \in L(Y)\right\}$.

The standard (multiplicative) Farrell approach views cost efficiency as originating from technical efficiency and allocative efficiency. Specifically, we have:

$$
\underbrace{\frac{C_{L}(Y, W)}{\sum_{i=1}^{m} w_{i} X_{i}}}_{\text {Cost Efficiency }}=\underbrace{\frac{1}{D_{L}^{\prime}(X, Y)}}_{\text {Technical Efficiency }} \cdot \underbrace{A E_{L}^{F}(X, Y ; W)}_{\text {Allocative Efficiency }},
$$

where $D_{L}^{\prime}(X, Y)=\sup \{\theta>0: X / \theta \in L(Y)\}$ is the Shephard input distance function (Shephard, 1953) and allocative efficiency is defined residually. We use the subscript $L$ to denote that we do not assume a specific type of returns to scale. Nevertheless, we will refer to $C_{c}(Y, W)$ and $D_{c}^{\prime}(X, Y)$ for $C R S$, and $C_{v}(Y, W)$ and $D_{v}^{\prime}(X, Y)$ for variable returns to scale (VRS) when needed. Additionally, it is well-known in DEA that the inverse of $D_{L}^{\prime}(X, Y)$ coincides with $\operatorname{ITE}_{L}\left(X_{k}, Y_{k}\right)$. For the particular case of CRS-program (1): $\operatorname{ITE}_{c}\left(X_{k}, Y_{k}\right)=D_{c}^{\prime}(X, Y)^{-1}$.

Considering actual common market prices for all firms within an industry, then the natural way of comparing the performance of each one would be using the left-hand side in (4). We then could assess the obtained values for each firm since we were using the same reference weights (prices) for all the observations, creating a market based ranking. This idea inspired Aparicio and Zofío (2019), who suggest that cross-efficiency in DEA could be also defined based on the notion of Farrell's cost efficiency. In particular, for a given set of any reference prices (e.g., shadow prices, market prices or other imputed prices), they define the Farrell (cost) cross-efficiency of unit / with respect to unit $k$ as

$$
\operatorname{FCE}_{L}\left(X_{l}, Y_{l} \mid k\right)=\frac{C_{L}\left(Y_{l}, V_{k}^{*}\right)}{\sum_{i=1}^{m} v_{i k}^{*} x_{i l}}
$$

where $L \in\{c, v\}$ denotes either constant or variable returns to scale.

As in (4), $F C E_{L}\left(X_{1}, Y_{l} \mid k\right)=\frac{1}{D_{L}\left(X_{l}, Y_{l}\right)} \cdot A E_{L}^{F}\left(X_{l}, Y_{i} ; V_{k}^{*}\right)$. Therefore, Farrell crossefficiency of unit / with respect to unit $k$ corrects the usual technical efficiency, the inverse 
of the Shephard distance function, through a term with meaning of (shadow) allocative efficiency.

Given the observed $n$ units, the traditional literature on cross-efficiency suggests to aggregate bilateral cross-efficiencies through the arithmetic mean to obtain the multilateral notion of cross efficiency. In the case of the Farrell cross-efficiency this yields:

$$
F C E_{L}\left(X_{l}, Y_{l}\right)=\frac{1}{n} \sum_{k=1}^{n} F C E_{L}\left(X_{l}, Y_{l} \mid k\right)=\frac{1}{n} \sum_{k=1}^{n} \frac{C_{L}\left(Y_{l}, V_{k}^{*}\right)}{\sum_{i=1}^{m} v_{i k}^{*} X_{i l}}
$$

Additionally, $F C E_{L}\left(X_{l}, Y_{l}\right)$ can be always decomposed (under any returns to scale) into (radial) technical efficiency and a correction factor defined as the arithmetic mean of $n$ shadow allocative efficiency terms. I.e.,

$$
F C E_{L}\left(X_{l}, Y_{l}\right)=\frac{1}{n} \sum_{k=1}^{n} F C E_{L}\left(X_{l}, Y_{l} \mid k\right)=\frac{1}{n} \sum_{k=1}^{n} \frac{C_{L}\left(Y_{l}, V_{k}^{*}\right)}{\sum_{i=1}^{m} v_{i k}^{*} X_{i l}}=I T E_{L}\left(X_{l}, Y_{l}\right) \cdot \frac{1}{n} \sum_{k=1}^{n} A E_{L}^{F}\left(X_{l}, Y_{l} ; V_{k}^{*}\right),(7)
$$

with $\operatorname{ITE}_{L}\left(X_{l}, Y_{l}\right)$ and $A E_{L}^{F}\left(X_{l}, Y_{l} ; V_{k}^{*}\right), L \in\{C, v\}$, denoting constant and variable returns to scale technical and (shadow) allocative efficiencies, respectively.

We note that $F C E_{L}\left(X_{l}, Y_{l}\right)$ satisfies two very interesting properties:

First, assuming the existence of perfectly competitive input markets resulting in a single equilibrium price for each input (i.e., firms are price takers), if we substitute (shadow) prices by these market prices in (7), then $\operatorname{FCE}_{L}\left(X_{l}, Y_{l}\right)$ precisely coincides with $C_{L}\left(Y_{l}, W\right) / \sum_{i=1}^{m} w_{i} x_{i l}$, which is Farrell's measure of cost inefficiency (4). Hence, economic cross-efficiency offers a 'natural' counterpart to consistently rank units when reference prices are unique for all units. This property is not satisfied in general by the standard measure of cross-efficiency, if both input and output market prices are used as weights; i.e., $\operatorname{CITE}_{c}\left(X_{l}, Y_{l}\right)=\frac{\sum_{r=1}^{s} p_{r} y_{r l}}{\sum_{i=1}^{m} w_{i} x_{i l}} \neq \frac{C_{c}\left(Y_{l}, W\right)}{\sum_{i=1}^{m} w_{i} x_{i l}}$. Indeed Aparicio and Zofío (2019) show that besides market prices, input homotheticity is required for the equality to hold; otherwise $\operatorname{CITE}_{c}\left(X_{l}, Y_{l}\right) \geq \operatorname{FCE}_{c}\left(X_{l}, Y_{l}\right)$. Nevertheless, we also remark that the concept of economic cross-efficiency can accommodate firm-specific market prices if some degree of market power exists and firms are price makers in the inputs markets. In that 
case individual firms' shadow prices would be substituted by their market counterparts in (7). This connects our proposal to the extensive theoretical and empirical economic efficiency literature considering individual market prices, e.g., Ali and Seiford (1993).

Second, as previously remarked, $F C E_{L}\left(X_{l}, Y_{l}\right)$ is well-defined, ranging between zero and one, even under variable returns to scale. This property is not verified in general by the standard cross-efficiency measures (see Wu et al., 2009, Lim and Zhu, 2015). This is quite relevant because traditional measures may yield negative values under variable returns to scale, which is inconsistent and hinders the extension of cross-efficiency methods to technologies characterized by VRS.

An interesting by-product of the economic cross-efficiency approach is that by incorporating the economic behavior of firms in the formulations (e.g., cost minimizers in $\left.F C E_{v}\left(X_{l}, Y_{l}\right)\right)$, the set of weights represented by the shadow prices are reinterpreted as market prices, rather than their usual reading in terms of the alternative supporting technological hyperplanes that they define, and against which technical inefficiency is measured. This solves some recent criticism raised against the cross-efficiency methods, since shadow prices could be then considered as specific realizations of market prices, e.g., see Førsund (2018a, 2018b) and Olesen (2018).

Next, we briefly introduce the Nerlovian cross-inefficiency.

\subsection{Nerlovian (profit) cross-inefficiency}

Now, we recall the concepts of profit inefficiency and its dual graph measure corresponding to the directional distance function (Chambers et al., 1998).

Given the vector of input and output market prices $(W, P) \in R_{+}^{m+s}$, and the production possibility set $T$, the profit function is defined as $\Pi_{T}(W, P)=\max _{X, Y}\left\{\sum_{r=1}^{s} p_{r} y_{r}-\sum_{i=1}^{m} w_{i} x_{i}:(X, Y) \in T\right\}$. In what follows, let $\Pi_{c}(W, P)$ and $\Pi_{v}(W, P)$ be the maximum profit given the CRS technology $T_{c}$ and the VRS technology $T_{v}$, respectively.

Profit inefficiency à la Nerlove for firm $k$ is defined as maximum profit (i.e., the value of the profit function given market prices) minus observed profit, normalized by the value of a pre-fixed reference vector $\left(G^{x}, G^{y}\right) \in R_{+}^{m+s}$. By duality, the following inequality is obtained (Chambers et al., 1998): 


$$
\frac{\Pi_{T}(W, P)-\left(\sum_{r=1}^{s} p_{r} y_{r k}-\sum_{i=1}^{m} w_{i} x_{i k}\right)}{\sum_{r=1}^{s} p_{r} g_{r}^{y}+\sum_{i=1}^{m} w_{i} g_{i}^{x}} \geq \vec{D}_{T}\left(X_{k}, Y_{k} ; G^{x}, G^{y}\right)
$$

where $\vec{D}_{T}\left(X_{k}, Y_{k} ; G^{x}, G^{y}\right)=\max _{\beta}\left\{\beta:\left(X_{k}-\beta G^{x}, Y_{k}+\beta G^{y}\right) \in T\right\}$ is the directional distance function. As for the Farrell approach, profit inefficiency can be also decomposed into technical inefficiency and allocative inefficiency, where the former corresponds to the directional distance function:

$$
\frac{\Pi_{T}(W, P)-\left(\sum_{r=1}^{s} p_{r} y_{r k}-\sum_{i=1}^{m} w_{i} x_{i k}\right)}{\sum_{r=1}^{s} p_{r} g_{r}^{y}+\sum_{i=1}^{m} w_{i} g_{i}^{x}}=\vec{D}_{T}\left(X_{k}, Y_{k} ; G^{x}, G^{y}\right)+A l_{T}^{N}\left(X_{k}, Y_{k} ; W, P ; G^{x}, G^{y}\right) .
$$

The subscript $T$ in $\Pi_{T}(W, P), \quad \vec{D}_{T}\left(X_{k}, Y_{k} ; G^{x}, G^{y}\right)$ and $A I_{T}^{N}\left(X_{k}, Y_{k} ; W, P ; G^{x}, G^{y}\right)$ implies that we do not assume a specific type of returns to scale. Nevertheless, as before we will use $\vec{D}_{c}\left(X_{k}, Y_{k} ; G^{x}, G^{y}\right)$ and $A l_{c}^{N}\left(X_{k}, Y_{k} ; W, P ; G^{x}, G^{y}\right)$ for CRS and $\vec{D}_{v}\left(X_{k}, Y_{k} ; G^{x}, G^{y}\right)$ and $A I_{v}^{N}\left(X_{k}, Y_{k} ; W, P ; G^{x}, G^{y}\right)$ for VRS.

In the case of DEA, when VRS is assumed, the directional distance function is determined through (10):

$$
\begin{aligned}
& \vec{D}_{v}\left(X_{k}, Y_{k} ; G^{x}, G^{y}\right)=\max _{\beta, \lambda} \beta \\
& \text { s.t } \sum_{j=1}^{n} \lambda_{j} x_{i j} \leq x_{i k}-\beta g_{i}^{x}, \quad i=1, \ldots, m, \\
& \sum_{j=1}^{n} \lambda_{j} y_{r j} \geq y_{r k}+\beta g_{r}^{y}, \quad r=1, \ldots, s, \\
& \sum_{j=1}^{n} \lambda_{j}=1 \\
& \lambda_{j} \geq 0, \quad j=1, \ldots, n \text {. }
\end{aligned}
$$

whose dual is: 


$$
\begin{array}{ll}
\min _{U, V, \alpha} & -\sum_{r=1}^{s} u_{r} y_{r k}+\sum_{i=1}^{m} v_{i} x_{i k}+\alpha \\
\text { s.t. } & \sum_{r=1}^{s} u_{r} y_{r j}-\sum_{i=1}^{m} v_{i} x_{i j}-\alpha \leq 0, \quad j=1, \ldots, n, \\
& \sum_{r=1}^{s} u_{r} g_{r}^{y}+\sum_{i=1}^{m} v_{i} g_{i}^{x}=1, \\
& U \geq 0_{s}, V \geq 0_{m} .
\end{array}
$$

Let also denote the optimal solutions of problem (11) as $\left(\vec{V}_{k}^{*}, \vec{U}_{k}^{*}, \vec{\alpha}_{k}^{*}\right)$.

Aparicio and Zofío (2019) defined the Nerlovian cross-inefficiency of unit / with respect to unit $k$ as:

$$
N C I_{v}\left(X_{l}, Y_{l} ; G^{x}, G^{y} \mid k\right)=\frac{\Pi\left(\vec{V}_{k}^{*}, \vec{U}_{k}^{*}\right)-\left(\sum_{r=1}^{s} \vec{u}_{r k}^{*} y_{r l}-\sum_{i=1}^{m} \vec{v}_{i k}^{*} x_{i l}\right)}{\sum_{r=1}^{s} \vec{u}_{r k}^{*} g_{r}^{y}+\sum_{i=1}^{m} \vec{v}_{i k}^{*} g_{i}^{x}}=\frac{\vec{\alpha}_{k}^{*}-\left(\sum_{r=1}^{s} \vec{u}_{r k}^{*} y_{r l}-\sum_{i=1}^{m} \vec{v}_{i k}^{*} x_{i l}\right)}{\sum_{r=1}^{s} \vec{u}_{r k}^{*} g_{r}^{y}+\sum_{i=1}^{m} \vec{v}_{i k}^{*} g_{i}^{x}} .
$$

As usual, the arithmetic mean of (12) for all observed units yields the final Nerlovian cross-inefficiency of unit $l$ :

$$
N C I_{v}\left(X_{l}, Y_{l} ; G^{x}, G^{y}\right)=\frac{1}{n} \sum_{k=1}^{n} N C I_{v}\left(X_{l}, Y_{i} ; G^{x}, G^{y} \mid k\right)
$$

Invoking (9), we observed once again that the Nerlovian cross-inefficiency of firm I is a 'correction' of the original directional distance function value for the unit under evaluation, where the modifying factor can be interpreted as (shadow) allocative inefficiency:

$$
N C I_{v}\left(X_{1}, Y_{i} ; G^{x}, G^{y}\right)=\vec{D}_{v}\left(X_{0}, Y_{0} ; G^{x}, G^{y}\right)+\frac{1}{n} \sum_{k=1}^{n} A I_{v}^{N}\left(X_{1}, Y_{i} ; \vec{V}_{k}^{*}, \vec{U}_{k}^{*} ; G^{x}, G^{y}\right)
$$

Finally, these authors showed that the approach by Ruiz (2013), based on the directional distance function under CRS, is a particular case of (14). 


\section{New economic cross-(in)efficiency measures}

\subsection{Profitability cross-efficiency}

We now extend the previous framework of economic cross-(in)efficiency to a set of new measures which can be decomposed either multiplicatively or additively. We start with the notion of profitability-corresponding to Georgescu-Roegen's (1951) 'return to the dollar', defined as the ratio of observed revenue to observed cost. We then show that it can be decomposed into a measure of economic efficiency represented by the generalized distance function introduced by Chavas and Cox (1999), and a factor defined as the geometric mean of the allocative efficiencies corresponding to the $n$ shadow prices. Let us define maximum profitability as $\mathrm{P}_{T}(W, P)=$

$$
\begin{gathered}
\max _{X, Y}\left\{\sum_{r=1}^{s} p_{r} y_{r} / \sum_{i=1}^{m} w_{i} x_{i}:(X, Y) \in T\right\} . \text { Zofío and Prieto (2006) proved that } \\
\frac{P \cdot Y_{k} / W \cdot X_{k}}{\mathrm{P}_{T}(W, P)} \leq D_{c}^{G}\left(X_{k}, Y_{k} ; \gamma\right),
\end{gathered}
$$

where $D_{c}^{G}\left(X_{k}, Y_{k} ; \gamma\right)=\inf \left\{\delta:\left(\delta^{\gamma} X_{k}, Y_{k} / \delta^{1-\gamma}\right) \in T\right\}, 0 \leq \gamma \leq 1$, is the generalized distance function and $P \cdot Y_{k}=\sum_{r=1}^{s} p_{r} y_{r k}$ and $W \cdot X_{k}=\sum_{i=1}^{m} w_{i} x_{i k}$.

We remark that the generalized distance function in expression (15), rather than being defined to allow for either constant or variable returns to scale as in the previous models, is characterized by the former. The reason is that the production technology exhibits local constant returns to scale at the optimum; hence maximum profitability is achieved at loci representing most productive scale sizes in Banker et al. (1984) terminology. This provides the rationale to develop the duality underlying expression (15) departing from such technological specification. We further justify this choice in what follows when recalling the variable returns to scale technology so as to account for scale efficiency.

The generalized distance function $D_{c}^{G}\left(X_{k}, X_{k} ; \gamma\right)$ can be calculated relying on DEA by solving the following non-linear problem: 


$$
\begin{aligned}
D_{c}^{G}\left(X_{k}, Y_{k} ; \gamma\right)= & \min _{\delta, \lambda} \delta \\
& \text { s.t. } \\
& \sum_{j=1}^{n} \lambda_{j} x_{i j} \leq \delta^{1-\gamma} x_{i k}, \quad i=1, \ldots, m, \\
& \sum_{j=1}^{n} \lambda_{j} y_{r j} \geq \frac{y_{r k}}{\delta^{\gamma}}, \quad r=1, \ldots, s, \\
& \lambda_{j} \geq 0, \\
& j=1, \ldots, n,
\end{aligned}
$$

Following the Farrell and Nerlovian decompositions (7) and (14), it is possible to define allocative efficiency as a residual from expression (15):

$$
\frac{P \cdot Y_{k} / W \cdot X_{k}}{\mathrm{P}_{T}(W, P)}=D_{c}^{G}\left(X_{k}, Y_{k} ; \gamma\right) \cdot A E_{c}^{G}\left(X_{k}, Y_{k} ; W, P ; \gamma\right)
$$

where $\quad A E_{c}^{G}\left(X_{K}, Y_{K} ; W, P ; \gamma\right)=\frac{P \cdot \hat{Y}_{k} / W \cdot \hat{X}_{k}}{\mathrm{P}_{T}(W, P)} \quad$ with $\quad \hat{X}_{k}=D_{c}^{G}\left(X_{k}, Y_{k} ; \gamma\right) X_{k} \quad$ and $\hat{Y}_{k}=Y_{k} / D_{c}^{G}\left(X_{k}, Y_{k} ; \gamma\right){ }^{4}$ So, allocative efficiency, which is a measure that in the Farrell approach essentially captures the comparison of the rate of substitution between production inputs with the ratio of market prices at the production isoquant given the output level $Y_{k}$, is, in this case, the profitability calculated at the (efficient) projection linked to the generalized model.

As previously mentioned, since the technology may be characterized by variable returns to scale, it is possible to bring its associated directional distance function $D_{v}^{G}\left(X_{k}, X_{k} ; \gamma\right)$ into (17)—calculated as in (16) but adding the VRS constraint $\sum_{j=1}^{n} \lambda_{j}=$ 1. This allows decomposing productive efficiency into two factors, one representing 'pure' VRS technical efficiency and a second one capturing scale efficiency: i.e., $D_{c}^{G}\left(X_{k}, X_{k} ; \gamma\right)$ $=\quad D_{v}^{G}\left(X_{k}, X_{k} ; \gamma\right) \cdot S^{G}\left(X_{k}, X_{k} ; \gamma\right)$, where $\quad S^{G}\left(X_{k}, X_{k} ; \gamma\right) \quad=$ $D_{c}^{G}\left(X_{k}, X_{k} ; \gamma\right) / D_{v}^{G}\left(X_{k}, X_{k} ; \gamma\right)$. Defining expression (15) under constant returns to scale enables us to individualize the contribution that scale efficiency makes to profitability efficiency. Otherwise, had we directly relied on the directional distance function defined

\footnotetext{
${ }^{4}$ Färe et al. (2002) defined this relationship in terms of the hyperbolic distance function; i.e., $D_{c}^{H}\left(X_{k}, Y_{k}\right)=\min _{\delta, z}\left\{\delta: \sum_{j=1}^{n} \lambda_{j} X_{j} \leq \delta X_{k}, \frac{Y_{k}}{\delta} \leq \sum_{j=1}^{n} \lambda_{j} Y_{j}, \lambda_{j} \geq 0, j=1, \ldots, n\right\}$.
} 
under variable returns to scale in (15), scale inefficiency would had been confounded with allocative efficiency in (17).

Reinterpreting the left hand side of (15) in the framework of cross-efficiency, we next define a new economic cross-efficiency approach that allows us to compare the (bilateral) performance of firms / with respect firm $k$ using the notion of profitability:

$$
\operatorname{PCE}_{c}\left(X_{1}, Y_{l} ; \gamma \mid k\right)=\frac{U_{k}^{*} \cdot Y_{1} / V_{k}^{*} \cdot X_{1}}{\mathrm{P}_{T}\left(V_{k}^{*}, U_{k}^{*}\right)}
$$

where, once again, $\left(V_{k}^{*}, U_{k}^{*}\right)$ are the shadow prices associated with the frontier projections generated by $D_{c}^{G}\left(X_{k}, X_{k} ; \gamma\right)$.

To aggregate all cross-efficiencies in a multiplicative framework we depart on this occasion from standard practice and use the geometric mean, whose properties make the aggregation meaningful when consistent (transitive) bilateral comparisons of performance in terms of productivity are pursued, see Aczél and Roberts (1989) and Balk et al. (2017). Hence:

$$
P C E_{c}\left(X_{l}, Y_{i} ; \gamma\right)=\left(\prod_{k=1}^{n} \frac{U_{k}^{*} \cdot Y_{l} / V_{k}^{*} \cdot X_{l}}{\mathrm{P}_{T}\left(V_{k}^{*}, U_{k}^{*}\right)}\right)^{1 / n},
$$

As in the Farrell and Nerlovian models (7) and (14), we can decompose $P C E_{c}\left(X_{1}, Y_{i} ; \gamma\right)$ according to technical and allocative criteria, thereby obtaining:

$$
P C E_{c}\left(X_{l}, Y_{l} ; \gamma\right)=D_{c}^{G}\left(X_{k}, Y_{k} ; \gamma\right) \cdot\left(\prod_{k=1}^{n} A E_{c}^{G}\left(X_{k}, Y_{k} ; V_{k}^{*}, U_{k}^{*} ; \gamma\right)\right)^{1 / n}
$$

Based on this decomposition, the role played by VRS technical efficiency and scale efficiency can be further individualized since $D_{C}^{G}\left(X_{k}, X_{k} ; \gamma\right)=$ $D_{v}^{G}\left(X_{k}, X_{k} ; \gamma\right) \cdot S E^{G}\left(X_{k}, X_{k} ; \gamma\right)$.

We now obtain some relevant relationships between the profit and profitability cross(in)efficiencies. Relaying on Färe et al. (2002) and Zofío and Prieto (2006), it is possible to show that under constant returns to scale, maximum feasible profit is zero, $\Pi_{c}(W, P)$ 
$=0$ (if $\left.\Pi_{c}(W, P)<+\infty\right)$, and, therefore, maximum profitability is one, $\mathrm{P}_{c}(W, P)=1 .{ }^{5}$ Also, it is a well-known result that, under CRS, ITE $E_{c}\left(X_{k}, Y_{k}\right)=D_{c}^{G}\left(X_{k}, Y_{k} ; 0\right) .{ }^{6}$ Combining both conditions, it is possible to express (17) as follows:

$$
\frac{P \cdot Y_{k}}{W \cdot X_{k}}=I T E_{c}\left(X_{k}, Y_{k}\right) \cdot A E_{c}^{G}\left(X_{k}, Y_{k} ; W, P ; 0\right)
$$

Now, in the usual cross-efficiency context considering $k$ 's shadow prices $\left(V_{k}^{*}, U_{k}^{*}\right)$ when evaluating the performance of firm $I$, we first have that the standard input oriented bilateral cross-efficiency can be interpreted as a profitability measure: $\operatorname{CITE}_{c}\left(X_{l}, Y_{l} \mid k\right)=\frac{U_{k}^{*} \cdot Y_{I}}{V_{k}^{*} \cdot Y_{I}}$. Second, $\operatorname{CITE}_{c}\left(X_{l}, Y_{l}\right)=\frac{1}{n} \sum_{k=1}^{n} \frac{U_{k}^{*} \cdot Y_{I}}{V_{k}^{*} \cdot X_{I}}$ is the arithmetic mean of the $n$ individual profitabilities [see (3)]. Additionally, by (21), we obtain the following decomposition of $\operatorname{CITE}_{c}\left(X_{1}, Y_{l}\right)$ :

$$
\operatorname{CITE}_{c}\left(X_{l}, Y_{l}\right)=\frac{1}{n} \sum_{k=1}^{n} \frac{U_{k}^{*} \cdot Y_{l}}{V_{k}^{*} \cdot X_{l}}=I T E_{c}\left(X_{l}, Y_{l}\right) \cdot\left[\frac{1}{n} \sum_{k=1}^{n} A E_{c}^{G}\left(X_{l}, Y_{l} ; V_{k}^{*}, U_{k}^{*} ; \gamma=0\right)\right] .
$$

Hence, under the assumption of $\mathrm{CRS}, \operatorname{CITE}_{c}\left(X_{1}, Y_{l}\right)$ can be decomposed as $\operatorname{FCE}_{L}\left(X_{1}, Y_{l}\right)$ into two technical and allocative factors, expression (7). Indeed, CRS implies that the production technology is input-homothetic and Aparicio and Zofío (2019) show in their Theorem 1 that in this (less restrictive) case, $\operatorname{CITE}_{c}\left(X_{l}, Y_{l}\right)=\operatorname{FCE}_{c}\left(X_{l}, Y_{l}\right)$ , and therefore (22) coincides with (7). Consequently, as in the latter expression, the classical input cross-inefficiency measure is equal to the self-appraisal score of firm $I$, $\operatorname{ITE}_{c}\left(X_{1}, Y_{l}\right)$, modified by the mean of its (shadow) generalized-allocative efficiencies. Note also that, as per (20), technical efficiency can be decomposed into VRS and scale efficiencies: $\operatorname{ITE}_{c}\left(X_{l}, Y_{l}\right)=\operatorname{ITE}\left(X_{l}, Y_{l}\right) \cdot \operatorname{SE}^{F}\left(X_{l}, Y_{l}\right)$.

Finally, it is also worth mentioning that the profit and profitability dualities and their associated economic cross-inefficiencies, including their decompositions, can be directly

\footnotetext{
${ }^{5}$ Aparicio and Zofío (2019) show in their Lemma 2 that given an optimal solution to problem (1), $\left(V_{k}^{*}, U_{k}^{*}\right)$, then $\Pi_{c}\left(V_{k}^{*}, U_{k}^{*}\right)=0$, i.e., maximum profit equal to infinitum can be discarded.
}

${ }^{6}$ In terms of the hyperbolic distance function, $\operatorname{ITE}_{c}\left(X_{k}, Y_{k}\right)=D_{c}^{H}\left(X_{k}, Y_{k}\right)^{2}$. 
related in the case of CRS. Following Färe et al. (2002:673), the precursor of expression (15) in terms of the profit function is:

$$
\Pi_{T}(W, P) \geq \frac{P \cdot Y_{1}}{D_{c}^{G}\left(X_{1}, Y_{i} ; \gamma\right)^{\gamma}}-D_{c}^{G}\left(X_{1}, Y_{i} ; \gamma\right)^{1-\gamma} W \cdot X_{l}
$$

Since $\Pi_{T}(W, P)=0$ in the case of CRS, expression (15) is easily derived from (23) and vice versa. However, under VRS, $\Pi_{T}(W, P)$ is not nil and we cannot obtain the duality based inequality (15), with the left-hand side not depending on any efficiency measure (distance function) and the right-hand side not depending on prices. This shows, once again, the importance of defining multiplicative economic cross-efficiency measures under the assumption of VRS.

\subsection{Farrell (revenue) cross-efficiency}

Following the same procedure set out to define the Farrell (cost) cross-efficiency, $F C E_{L}\left(X_{l}, Y_{l}\right)$ in (6), we can develop an output-oriented approach in terms of the radial output technical efficiency, $\mathrm{OTE}_{c}\left(X_{k}, Y_{k}\right)$ under CRS calculated through a DEA program corresponding to the inverse of (1) - see Ali and Seiford (1993), and the revenue function. As usual, $\operatorname{OTE}_{v}\left(X_{k}, Y_{k}\right)$ may be computed under VRS adding the constraint $\sum_{j=1}^{n} \lambda_{j}=1$

The standard output technical cross-efficiency of $I$ based on the optimal weights - shadow prices - of $k,\left(V_{k}^{*}, U_{k}^{*}\right)$, defines as:

$$
\operatorname{COTE}_{c}\left(X_{l}, Y_{l} \mid k\right)=\frac{V_{k}^{*} \cdot X_{I}}{U_{k}^{*} \cdot Y_{I}}=\frac{\sum_{i=1}^{m} v_{i k}^{*} x_{i l}}{\sum_{r=1}^{s} u_{r k}^{*} y_{r l}}
$$

The introduction of the Farrell (revenue) cross-efficiency requires defining the output requirement set $P(X)$ as the set of non-negative outputs $Y \in R_{+}^{s}$ that can be produced with non-negative inputs $X \in R_{+}^{m}$, formally $P(X)=\left\{Y \in R_{+}^{s}:(X, Y) \in T\right\}$, and the isoquant of $P(X): \operatorname{Isoq} P(X):=\{Y \in P(X): \varepsilon>1 \Rightarrow \varepsilon Y \notin P(X)\}$. Let us also denote by $R_{L}(X, P)$ the maximum revenue obtained from using input level $X$ given the 
output market price vector $P \in R_{++}^{s}: R_{L}(X, P)=\max _{Y}\left\{\sum_{i=1}^{s} p_{s} y_{s}: Y \in P(X)\right\}$. The standard revenue definition and decomposition is given by:

$$
\underbrace{\frac{R_{L}(X, P)}{\sum_{i=1}^{s} p_{s} y_{s}}}_{\text {Revenue Efficiency }}=\underbrace{\frac{1}{D_{L}^{O}(X, Y)}}_{\text {Technical Efficiency }} \cdot \underbrace{A E_{L}^{F}(X, Y ; P)}_{\text {Allocative Efficiency }},
$$

where $D_{L}^{O}(X, Y)=\inf \{\phi>0: Y / \phi \in P(X)\}$ is the Shephard output distance function (Shephard, 1953) and allocative efficiency is defined residually. Again, we use the subscript $L$ to stress that revenue efficiency can be defined with respect to different returns to scale.

Consequently, considering shadow prices, the Farrell (revenue) cross-efficiency of firm / with respect to firm $k$ is:

$$
F R E_{L}\left(X_{l}, Y_{1} \mid k\right)=\frac{R_{L}\left(X_{1}, U_{k}^{*}\right)}{U_{k}^{*} \cdot Y_{l}}=\frac{R_{L}\left(X_{l}, U_{k}^{*}\right)}{\sum_{r=1}^{s} u_{r k}^{*} y_{r l}},
$$

with $L \in\{c, v\}$ denoting constant and variable returns to scale, respectively.

As in (25), $F R E_{L}\left(X_{l}, Y_{l} \mid k\right)=\frac{1}{D_{L}^{O}\left(X_{l}, Y_{l}\right)} \cdot A E_{L}^{F}\left(X_{l}, Y_{i} ; U_{k}^{*}\right)$. Therefore, Farrell revenue cross-efficiency corrects the usual technical efficiency, the inverse of Shephard output distance function, through a term capturing (shadow) allocative efficiency.

As in the case of the Farrell cost cross-efficiency (6), we could aggregate all individual revenue cross-efficiencies following the standard approach that relies on the arithmetic mean. However, in the current multiplicative framework, we rely on our preferred choice for the geometric mean, already used in the profitability approach. This yields

$$
F R E_{L}\left(X_{l}, Y_{l}\right)=\left(\prod_{k=1}^{n} F R E_{L}\left(X_{l}, Y_{l} \mid k\right)\right)^{1 / n}=\left(\prod_{k=1}^{n} \frac{R_{L}\left(X_{l}, U_{k}^{*}\right)}{U_{k}^{*} \cdot Y_{l}}\right)^{1 / n}
$$

which can be further decomposed into technical and allocative components:

$$
\operatorname{FRE}_{L}\left(X_{l}, Y_{l}\right)=\left(\prod_{k=1}^{n} \frac{R_{L}\left(X_{l}, U_{k}^{*}\right)}{U_{k}^{*} \cdot Y_{l}}\right)^{1 / n}=\operatorname{OTE}_{L}\left(X_{l}, Y_{l}\right) \cdot\left(\prod_{k=1}^{n} A E_{L}^{F}\left(X_{l}, Y_{l} ; U_{k}^{*}\right)\right)^{1 / n}
$$


We now combine the cost and revenue approaches of economic cross-efficiency and relate it to the profitability cross-efficiency definition. Assume first that the $\operatorname{FCE}_{L}\left(X_{l}, Y_{l}\right)$ in (6) is defined using the geometric mean as aggregator-so it is consistent with $\operatorname{FRE}_{L}\left(X_{l}, Y_{l}\right)$ in (27). Then, given that $\operatorname{FCE}_{L}\left(X_{l}, Y_{l}\right)$ depends on (shadow) input prices but not on (shadow) output prices, and vice versa for $F R E_{L}\left(X_{l}, Y_{l}\right)$, we suggest to mix both approaches to introduce yet another new crossefficiency measure under the Farrell paradigm.

$$
F E_{L}\left(X_{l}, Y_{l}\right)=\frac{F C E_{L}\left(X_{l}, Y_{l}\right)}{F R E_{L}\left(X_{l}, Y_{l}\right)}=\frac{\left(\prod_{k=1}^{n} \frac{C_{L}\left(Y_{l}, V_{k}^{*}\right)}{V_{k}^{*} \cdot X_{l}}\right)^{1 / n}}{\left(\prod_{k=1}^{n} \frac{R_{L}\left(X_{l}, U_{k}^{*}\right)}{U_{k}^{*} \cdot Y_{l}}\right)^{1 / n}}=\frac{\operatorname{ITE}\left(X_{l}, Y_{l}\right) \cdot\left(\prod_{k=1}^{n} A E_{L}^{F}\left(X_{l}, Y_{l} ; V_{k}^{*}\right)\right)^{1 / n}}{\operatorname{OTE} E_{L}\left(X_{l}, Y_{l}\right) \cdot\left(\prod_{k=1}^{n} A E_{L}^{F}\left(X_{l}, Y_{l} ; U_{k}^{*}\right)\right)^{1 / n}}
$$

$F E_{L}\left(X_{l}, Y_{l}\right)$ is related to $\operatorname{CITE}_{c}\left(X_{l}, Y_{l} \mid k\right)$ under CRS:

$$
F E_{c}\left(X_{l}, Y_{l}\right)=\frac{\left(\prod_{k=1}^{n} \frac{U_{k}^{*} \cdot Y_{l}}{V_{k}^{*} \cdot X_{l}}\right)^{1 / n}}{\left(\prod_{k=1}^{n} \frac{R_{c}\left(X_{l}, U_{k}^{*}\right)}{C_{c}\left(Y_{l}, V_{k}^{*}\right)}\right)^{1 / n}}=\frac{\left(\prod_{k=1}^{n} \operatorname{CITE} E_{c}\left(X_{l}, Y \mid k\right)\right)^{1 / n}}{\left(\prod_{k=1}^{n} \frac{R_{c}\left(X_{l}, U_{k}^{*}\right)}{C_{c}\left(Y_{l}, V_{k}^{*}\right)}\right)^{1 / n}}
$$

The value of (30) must be close to

$$
\left(\prod_{k=1}^{n} \operatorname{CITE}_{c}\left(X_{l}, Y \mid k\right)\right)^{1 / n} /\left(\prod_{k=1}^{n} \mathrm{P}_{T}\left(V_{k}^{*}, U_{k}^{*}\right)\right)^{1 / n} .
$$

Additionally, $F E_{L}\left(X_{l}, Y_{l}\right)$ always takes values between zero and one, while $F E_{L}\left(X_{l}, Y_{l}\right) \leq \frac{I T E_{L}\left(X_{l}, Y_{l}\right)}{\operatorname{OTE}_{L}\left(X_{l}, Y_{l}\right)}$, under any returns to scale assumed.

At this point, it is worth mentioning that analogous results to the Farrell cost crossefficiency can be derived for the cross output technical efficiency and revenue efficiency when output-homotheticity is assumed; i.e., $\operatorname{COTE}_{c}\left(X_{l}, Y_{l} \mid k\right)=F R E_{c}\left(X_{l}, Y_{l} \mid k\right)$. However, $\operatorname{COTE}_{c}\left(X_{l}, Y_{l}\right) \neq \operatorname{FRE}_{c}\left(X_{l}, Y_{l}\right)$ in general if $\operatorname{COTE}_{c}\left(X_{l}, Y_{l}\right)$ is defined as usual by additive aggregation and $F R E_{c}\left(X_{l}, Y_{l}\right)$ is defined through multiplicative aggregation. 


\subsection{Profit cross-inefficiency based on the (weighted) additive distance function}

This section introduces a measure of economic cross-efficiency based on the weighted additive distance function, which constitutes an alternative to the Nerlovian definition based on the directional distance function.

Cooper et al. (2011) proved that

$$
\frac{\Pi_{T}(W, P)-\left(\sum_{r=1}^{s} p_{r} y_{r k}-\sum_{i=1}^{m} w_{i} x_{i k}\right)}{\min \left\{\frac{w_{1}}{a_{1 k}}, \ldots, \frac{w_{m}}{a_{m k}}, \frac{p_{1}}{b_{1 k}}, \ldots, \frac{p_{s}}{b_{s k}}\right\}} \geq W A_{T}\left(X_{k}, Y_{k} ; A_{k}, B_{k}\right),
$$

where

$$
\begin{gathered}
W A_{v}\left(X_{k}, Y_{k} ; A_{k}, B_{k}\right)=\max _{S, H, \lambda_{j}}\left\{A_{k} \cdot S+B_{k} \cdot H: \sum_{j=1}^{n} \lambda_{j} x_{i j} \leq x_{i k}-S_{i}, \forall i, y_{r k}+h_{r} \leq \sum_{j=1}^{n} \lambda_{j} y_{r j},\right. \\
\left.\sum_{j=1}^{n} \lambda_{j}=1, \lambda_{j} \geq 0, j=1, \ldots, n, S \geq 0_{m}, H \geq 0_{s}\right\}
\end{gathered}
$$

is the weighted additive model in DEA. In particular, $A_{k}$ and $B_{k}$ are pre-fixed input and output weights, respectively. As in the Nerlovian approach (8), the left hand side of (32) measures profit inefficiency, defined as maximum profit (i.e., the value of the profit function at the market prices) minus observed profit, normalized by the minimum of the ratios of market prices to their corresponding pre-fixed weights. Based on (32), and assuming variable returns to scale, profit inefficiency for firm $k$ can be decomposed as follows:

$$
\frac{\Pi_{V}(W, P)-\left(\sum_{r=1}^{s} p_{r} y_{r k}-\sum_{i=1}^{m} w_{i} x_{i k}\right)}{\min \left\{\frac{w_{1}}{a_{1 k}}, \ldots, \frac{w_{m}}{a_{m k}}, \frac{p_{1}}{b_{1 k}}, \ldots, \frac{p_{s}}{b_{s k}}\right\}}=W A_{v}\left(X_{k}, Y_{k} ; A_{k}, B_{k}\right)+A I_{V}^{W}\left(X_{k}, Y_{k} ; W, P ; A_{k}, B_{k}\right)
$$

Substituting market prices by shadow prices ${ }^{7}$ in evaluating firm / with respect to firm $k$, we obtain:

\footnotetext{
${ }^{7}$ Shadow prices are obtained for $\mathrm{DMU}_{\mathrm{k}}$ through the linear dual of program (33).
} 


$$
W A C I_{v}\left(X_{l}, Y_{i} ; A_{l}, B_{l} \mid k\right)=\frac{\Pi_{v}\left(V_{k}^{*}, U_{k}^{*}\right)-\left(\sum_{r=1}^{s} u_{r k}^{*} y_{r l}-\sum_{i=1}^{m} v_{i k}^{*} x_{i l}\right)}{\min \left\{\frac{v_{1 k}^{*}}{a_{1 l}}, \ldots, \frac{v_{m k}^{*}}{a_{m l}}, \frac{u_{1 k}^{*}}{b_{1 l}}, \ldots, \frac{u_{s k}^{*}}{b_{s l}}\right\}} .
$$

Aggregating all profit cross-inefficiencies through the arithmetic mean-given the additive framework, allows us to define the new profit cross-inefficiency measure based on the weighted additive approach:

$$
W A C I_{v}\left(X_{l}, Y_{l} ; A_{l}, B_{l}\right)=\frac{1}{n} \sum_{k=1}^{n} \frac{\Pi_{v}\left(V_{k}^{*}, U_{k}^{*}\right)-\left(\sum_{r=1}^{s} u_{r k}^{*} y_{r l}-\sum_{i=1}^{m} v_{i k}^{*} x_{i l}\right)}{\min \left\{\frac{v_{1 k}^{*}}{a_{1 l}}, \ldots, \frac{v_{m k}^{*}}{a_{m l}}, \frac{u_{1 k}^{*}}{b_{1 l}}, \ldots, \frac{u_{s k}^{*}}{b_{s l}}\right\}},
$$

which can be decomposed as (34), yielding

$$
W A C I_{v}\left(X_{l}, Y_{l} ; A_{l}, B_{l}\right)=W A_{v}\left(X_{l}, Y_{l} ; A_{l}, B_{l}\right)+\frac{1}{n} \sum_{k=1}^{n} A I_{v}^{W}\left(X_{l}, Y_{l} ; V_{k}^{*}, U_{k}^{*} ; A_{l}, B_{l}\right)
$$

Therefore $\mathrm{WACl}_{T}\left(X_{l}, Y_{l} ; A_{l}, B_{l}\right)$ coincides with the sum of the original technical inefficiency measure of firm $I$, determined by the weighted additive model, and a correction factor capturing (shadow) allocative inefficiencies.

It is worth mentioning that, among all the approaches mentioned in this chapter, the weighted additive model is the unique such that measures technical efficiency with respect to the strongly efficient frontier, resorting to the notion of Pareto-Koopmans efficiency.

\subsection{Profit cross-inefficiency measure based on the Hölder distance function}

In this section we introduce a profit cross-inefficiency measure based on the Hölder distance function, thereby relating two streams of the literature: cross efficiency and least distance. Hölder distance functions were firstly introduced with the aim of relating the concepts of technical efficiency and metric distances (Briec, 1998).

The Hölder norms $\ell_{q}(q \in[1, \infty])$ are defined over a $g$-dimensional real normed space as follows: 


$$
\|\|_{q}: Z \rightarrow\|Z\|_{q}= \begin{cases}\left(\sum_{j=1}^{g}\left|z_{j}\right|^{q}\right)^{1 / q} & \text { if } \mathrm{q} \in[1, \infty[ \\ \max _{j=1, \ldots, g}\left\{\left|z_{j}\right|\right\} & \text { if } \mathrm{q}=\infty\end{cases}
$$

where $Z=\left(z_{1}, \ldots, z_{g}\right) \in R^{g}$. From (38), Briec (1998) define the Hölder distance function for firm $k$ with vector of inputs and outputs $\left(X_{k}, Y_{k}\right)$ as follows:

$$
D_{\|\|_{q}}\left(X_{k}, Y_{k}\right)=\inf _{X, Y}\left\{\left\|\left(\left(X_{k}, Y_{k}\right)\right)-(X, Y)\right\|_{q}:(X, Y) \in \partial(T)\right\} .
$$

Model (39) minimizes the distance from $\left(X_{k}, Y_{k}\right)$ to the weakly efficient frontier of the technology, denoted as $\partial(T)$, and is interpreted as a measure of technical inefficiency. Other related paper where Hölder distance functions have also been used linked to the weakly efficient frontier is Briec and Lesourd (1999).

After introducing some notation and definitions, we are ready to show that we can derive a difference-form measure of profit inefficiency from a duality result proven in Briec and Lesourd (1999).

Proposition 1. Let $\left(X_{k}, Y_{k}\right)$ an input-output vector in $T$. Let $\ell_{t}$ be the dual space of $\ell_{q}$ with $1 / q+1 / t=1$. Then,

$$
D_{\|\|_{q}}\left(X_{k}, Y_{k}\right)=\inf _{D, H}\left\{\Pi_{T}(D, H)-\left(\sum_{r=1}^{s} h_{r} y_{r k}-\sum_{i=1}^{m} d_{i} x_{i k}\right):\|(D, H)\|_{t} \geq 1, D \geq 0_{m}, H \geq 0_{s}\right\} .
$$

Proof. See Proposition 3.2 in Briec and Lesourd (1999).

By Proposition 1, it is obvious that if the input-output market prices $(W, P)$ are such that $\|(W, P)\|_{t} \geq 1$, then $\Pi_{T}(W, P)-\left(\sum_{r=1}^{s} p_{r} y_{r k}-\sum_{i=1}^{m} w_{i} x_{i k}\right) \geq D_{\|\|_{q}}\left(X_{k}, Y_{k}\right)$. We are then capable of obtaining the usual difference-form measure of profit inefficiency in the lefthand side of the inequality and the Hölder distance function in the right hand side, showing that it is possible to decompose overall inefficiency through $D_{\|\|_{q}}\left(X_{k}, Y_{k}\right)$. However, as with the previous proposals (8) and (32), profit inefficiency must be normalized (deflated) in order to obtain an appropriate measure - see Aparicio et al. (2016). Accordingly, we propose the following solution, which was proved in Aparicio et al. (2017a). 
Proposition 2. Let $\left(X_{k}, Y_{k}\right)$ an input-output vector in $T$. Let $\ell_{t}$ be the dual space of $\ell_{q}$ with $1 / q+1 / t=1$. Let $(W, P) \in R_{++}^{m+s}$. Then,

$$
\frac{\Pi_{T}(W, P)-\left(\sum_{r=1}^{s} w_{r} y_{r k}-\sum_{i=1}^{m} p_{i} x_{i k}\right)}{\|(W, P)\|_{t}} \geq D_{\|\|_{q}}\left(X_{k}, Y_{k}\right)
$$

As before, departing from (40), and assuming variable returns to scale, profit inefficiency for firm $k$ can be decomposed as follows:

$$
\frac{\Pi_{T}(W, P)-\left(\sum_{r=1}^{s} p_{r} y_{r k}-\sum_{i=1}^{m} w_{i} X_{i k}\right)}{\|(W, P)\|_{t}}=D_{\|\|_{q}}\left(X_{k}, Y_{k}\right)+A l_{V}^{\|\|_{q}}\left(X_{k}, Y_{k} ; W, P\right) .
$$

Considering shadow prices $^{8}$ rather than market prices when evaluating firm $/$ with respect to firm $k$, we obtain:

$$
H C I_{V}\left(X_{l}, Y_{1} \mid k\right)=\frac{\Pi_{v}\left(V_{k}^{*}, U_{k}^{*}\right)-\left(\sum_{r=1}^{s} u_{r k}^{*} y_{r l}-\sum_{i=1}^{m} v_{i k}^{*} x_{i l}\right)}{\left\|\left(V_{k}^{*}, U_{k}^{*}\right)\right\|_{t}}
$$

Then, aggregating all profit cross-inefficiencies through the arithmetic mean yields the new profit cross-efficiency measured based on the Hölder distance function:

$$
H C I_{v}\left(X_{l}, Y_{l}\right)=\frac{1}{n} \sum_{k=1}^{n} \frac{\Pi_{v}\left(V_{k}^{*}, U_{k}^{*}\right)-\left(\sum_{r=1}^{s} u_{r k}^{*} y_{r t}-\sum_{i=1}^{m} v_{i k}^{*} x_{i l}\right)}{\left\|\left(V_{k}^{*}, U_{k}^{*}\right)\right\|_{t}},
$$

which, once again, can be decomposed as (41), thereby obtaining

$$
\operatorname{HCl}_{v}\left(X_{l}, Y_{l}\right)=D_{\|\|_{q}}\left(X_{k}, Y_{k}\right)+\frac{1}{n} \sum_{k=1}^{n} A I_{v}^{\|\|_{q}}\left(X_{l}, Y_{l} ; V_{k}^{*}, U_{k}^{*}\right)
$$

\section{Extensions of economic cross-(in)efficiency to panel data}

We now briefly introduce extensions of the economic cross-efficiency models related to panel data with the aim of comparing the evolution of firms' performance over time.

${ }^{8}$ These shadow prices come from the optimization model that appears in Proposition 1. 
To this end, we rely on two proposals related to the Farrell (cost) and Nerlovian (profit) approaches. For the former, Maniadakis and Thanassoulis (2004) introduce the socalled cost Malmquist index:

$$
C M\left(X_{l}^{t}, Y_{I}^{t} ; X_{I}^{t+1}, Y_{I}^{t+1}\right)=\left[\left(\frac{W^{t} \cdot X^{t+1} / C_{c}^{t}\left(Y^{t+1}, W^{t}\right)}{W^{t} \cdot X^{t} / C_{c}^{t}\left(Y^{t}, W^{t}\right)}\right) \cdot\left(\frac{W^{t+1} \cdot X^{t+1} / C_{c}^{t+1}\left(Y^{t+1}, W^{t+1}\right)}{W^{t+1} \cdot X^{t} / C_{c}^{t+1}\left(Y^{t}, W^{t+1}\right)}\right)\right]^{1 / 2}
$$

where the superscripts $t$ and $t+1$ denote two different periods of time.

If we translate (45) to the cross-efficiency context considering shadow prices (those associated with the radial model in DEA), we get the following:

$$
C M_{c}\left(X_{l}^{t}, Y_{I}^{t} ; X_{I}^{t+1}, Y_{I}^{t+1} \mid k\right)=\left[\left(\frac{V_{k}^{* t} \cdot X_{I}^{t+1} / C_{c}^{t}\left(Y_{I}^{t+1}, V_{k}^{* t}\right)}{V_{k}^{* t} \cdot X_{I}^{t} / C_{c}^{t}\left(Y_{I}^{t}, V_{k}^{* t}\right)}\right) \cdot\left(\frac{V_{k}^{* t+1} \cdot X_{I}^{t+1} / C_{c}^{t+1}\left(Y_{I}^{t+1}, V_{k}^{* t+1}\right)}{V_{k}^{* t+1} \cdot x^{l t} / C_{c}^{t+1}\left(Y_{I}^{t}, V_{k}^{* t+1}\right)}\right)\right]
$$

In this way, we can introduce and decompose the cost Malmquist cross-efficiency index for firm $I$ as the geometric mean of $C M_{c}\left(X_{l}^{t}, Y_{l}^{t} ; X_{l}^{t+1}, Y_{I}^{t+1} \mid k\right)$ for all $k$ :

$$
C M_{c}\left(X_{l}^{t}, Y_{l}^{t} ; X_{l}^{t+1}, Y_{l}^{t+1}\right)=\left(\prod_{k=1}^{n} C M_{c}\left(X_{l}^{t}, Y_{l}^{t} ; X_{l}^{t+1}, Y_{l}^{t+1} \mid k\right)\right)^{1 / n}=\frac{I T E_{c}^{t}\left(X_{l}^{t}, Y_{I}^{t}\right)}{I T E_{c}^{t+1}\left(X_{l}^{t+1}, Y_{I}^{t+1}\right)} \cdot \Delta_{l}^{F},
$$

where $\Delta_{l}^{F}$ is a mix of technological, allocative efficiency and price changes over time.

For the Nerlovian cross-efficiency approach, Juo et al. (2015) define the change of normalized profit inefficiency from period $t$ to period $t+1$, and propose its decomposition into different sources. In particular, these authors introduce a profit-Luenberger indicator:

$$
\begin{gathered}
\Pi L_{T}\left(X_{l}^{t}, Y_{l}^{t} ; X_{l}^{t+1}, Y_{l}^{t+1} ; G_{l}^{x}, G_{l}^{y}\right)= \\
\frac{1}{2}\left\{\left[\frac{\Pi_{T}^{t}\left(W^{t}, P^{t}\right)-\left(P^{t} \cdot Y^{t}-W^{t} \cdot X^{t}\right)}{W^{t} \cdot G^{x}+P^{t} \cdot G^{y}}-\frac{\Pi_{T}^{t}\left(W^{t}, P^{t}\right)-\left(P^{t} \cdot Y^{t+1}-W^{t} \cdot X^{t+1}\right)}{W^{t} \cdot G^{x}+P^{t} \cdot G^{y}}\right]\right. \\
\left.+\left[\frac{\Pi_{T}^{t+1}\left(W^{t+1}, P^{t+1}\right)-\left(P^{t+1} \cdot Y^{t}-W^{t+1} \cdot X^{t}\right)}{W^{t+1} \cdot G^{x}+P^{t+1} \cdot G^{y}}-\frac{\Pi_{T}^{t+1}\left(W^{t+1}, P^{t+1}\right)-\left(P^{t+1} \cdot Y^{t+1}-W^{t+1} \cdot X^{t+1}\right)}{W^{t+1} \cdot G^{x}+P^{t+1} \cdot G^{y}}\right]\right\} .
\end{gathered}
$$

Accordingly, this definition can be reformulated for firm $/$ in terms of the shadow prices of firm $k$ (those related to the directional distance function), thereby obtaining: 


$$
\begin{aligned}
& \Pi L_{T}\left(X_{I}^{t}, Y_{I}^{t} ; X_{I}^{t+1}, Y_{I}^{t+1} ; G_{I}^{X}, G_{I}^{Y} \mid k\right) \\
& =\frac{1}{2}\left\{\left[\frac{\Pi_{T}^{t}\left(V_{k}^{* t}, U_{k}^{* t}\right)-\left(U_{k}^{* t} \cdot Y_{l}^{t}-V_{k}^{* t} \cdot X_{l}^{t}\right)}{V_{k}^{* t} \cdot G_{l}^{x}+U_{k}^{* t} \cdot G_{l}^{y}}-\frac{\Pi_{T}^{t}\left(V_{k}^{* t}, U_{k}^{* t}\right)-\left(U_{k}^{* t} \cdot Y_{1}^{t+1}-V_{k}^{* t} \cdot X_{I}^{t+1}\right)}{V_{k}^{* t} \cdot G_{l}^{x}+U_{k}^{* t} \cdot G_{l}^{y}}\right]\right. \\
& \left.+\left[\frac{\Pi_{T}^{t+1}\left(V_{k}^{* t+1}, U_{k}^{* t+1}\right)-\left(U_{k}^{* t+1} \cdot Y_{I}^{t}-V_{k}^{* t+1} \cdot X_{l}^{t}\right)}{V_{k}^{* t+1} \cdot G_{l}^{x}+U_{k}^{* t+1} \cdot G_{I}^{y}}-\frac{\Pi_{T}^{t+1}\left(V_{k}^{* t+1}, U_{k}^{* t+1}\right)-\left(U_{k}^{* t+1} \cdot Y_{I}^{t+1}-V_{k}^{* t+1} \cdot X_{l}^{t+1}\right)}{V_{k}^{* t+1} \cdot G_{I}^{x}+U_{k}^{* t+1} \cdot G_{I}^{y}}\right]\right\},
\end{aligned}
$$

and the final profit-Luenberger cross-inefficiency indicator for firm I is defined as:

$$
\Pi L_{T}\left(X_{I}^{t}, Y_{I}^{t} ; X_{I}^{t+1}, Y_{I}^{t+1} ; G_{I}^{x}, G_{I}^{y}\right)=\frac{1}{n} \sum_{k=1}^{n} \Pi L_{T}\left(X_{I}^{t}, Y_{I}^{t} ; X_{I}^{t+1}, Y_{I}^{t+1} ; G_{I}^{x}, G_{I}^{y} \mid k\right)
$$

Following Juo et al. (2015), $\Pi L_{T}$ can be decomposed into several components, mainly a Luenberger productivity indicator, which ultimately corresponds to a profitbased Bennet quantity indicator, and a price change term incorporating allocative inefficiency (see Balk, 2018). Likewise, the Luenberger productivity indicator may be decomposed into efficiency change and technical change. In particular, efficiency change coincides with the difference $D D F_{T}^{t}\left(X_{l}^{t}, Y_{l}^{t} ; G_{l}^{x}, G_{l}^{y}\right)-D D F_{T}^{t+1}\left(X_{l}^{t+1}, Y_{l}^{t+1} ; G_{l}^{x}, G_{l}^{y}\right)$. In this way, the profit-Luenberger cross-inefficiency for firm I would be decomposed into the change experienced by the DEA self-appraisal scores, the directional distance function value for firm $I$ in times $\mathrm{t}$ and $\mathrm{t}+1$, and a (shadow) correction factor $\Delta_{l}^{N}$ :

$$
\begin{gathered}
\Pi L_{T}\left(X_{l}^{t}, Y_{l}^{t} ; X_{l}^{t+1}, Y_{I}^{t+1} ; G_{l}^{x}, G_{l}^{y}\right)= \\
{\left[D D F_{T}^{t}\left(X_{l}^{t}, Y_{I}^{t} ; G_{I}^{x}, G_{l}^{y}\right)-D D F_{T}^{t+1}\left(X_{I}^{t+1}, Y_{I}^{t+1} ; G_{I}^{x}, G_{l}^{y}\right)\right]+\Delta_{l}^{N} .}
\end{gathered}
$$

As for other panel data economic cross-(in)efficiency models that can be related to existing literature, we note that a profitability efficiency change measure based on shadow prices, i.e., $P C E_{c}\left(X_{l}, Y_{i} ; \gamma\right)$, can be defined in terms of the Fisher index following Zofío and Prieto (2006). Also, following Aparicio et al. (2017b), it is possible to define a profit efficiency change measure using the economic cross-inefficiency model based on the weighted additive distance function $\operatorname{WACl}_{v}\left(X_{l}, Y_{l} ; A_{l}, B_{l}\right)$ alternative to the profit Luenberger indicator in (49). 


\section{Numerical examples: An application to banking data.}

To illustrate the new cross-(in)efficiency measures and their empirical implementation, we rely on a database on 20 Iranian branch banks observed in 2001, previously used by Akbarian (2015) to present a novel model that ranks observations combining cross-efficiency and analytic hierarchy process (AHP) methods. The database was compiled originally by Amirteimoori and Kordrostami (2005), who discuss the statistical sources and selected variables. Following these authors, the production process is characterized by three inputs and three outputs. Inputs are: I.1) number of staff (personnel); I.2), number of computer terminals; and I.3) branch size (square meters of premises). On the output side the following variables are considered: 0.1 ) deposits; O.2) amount of loans; and O.3) amount of charge. All output variables are stated in ten million of current Iranian Rials. The complete (normalized) dataset can be found in Amirteimoori and Kordrostami (2005:689), while Table 1 shows the descriptive statistics for all these variables.

Table 1. Descriptive statistics for inputs and outputs, 2001.

\begin{tabular}{l|c|c|c|c|c|c|}
\cline { 2 - 7 } & $\begin{array}{c}\text { Staff } \\
(\#)\end{array}$ & $\begin{array}{c}\text { Computer } \\
\text { Terminals } \\
(\#)\end{array}$ & $\begin{array}{c}\text { Space } \\
(\mathrm{m} 2)\end{array}$ & Deposits & Loans & Charge \\
\hline Average & 0.738 & 0.713 & 0.368 & 0.191 & 0.549 & 0.367 \\
\hline Median & 0.752 & 0.675 & 0.323 & 0.160 & 0.562 & 0.277 \\
\hline Minimum & 0.372 & 0.550 & 0.120 & 0.039 & 0.184 & 0.049 \\
\hline Maximum & 1.000 & 1.000 & 1.000 & 1.000 & 1.000 & 1.000 \\
\hline Stand. Dev. & 0.160 & 0.138 & 0.207 & 0.200 & 0.261 & 0.257 \\
\hline
\end{tabular}

Source: Amirteimoori and Kordrostami (2005).

In the empirical application, we illustrate the most representative multiplicative and additive models of economic cross-efficiency. In particular the Farrell cost model based on the (inverse) of the input distance function, the profit approach based on the directional distance function (Nerlove), the weighted additive distance function, and the Hölder distance function, as well as the profitability definition based on the generalized distance function. We leave the Farrell revenue model and panel data implementations of the cost Malmquist index and profit Luenberger indicator as exercises to the interested readers. 


\subsection{Farrell (cost) and Nerlovian (profit) economic cross-efficiency}

For comparison purposes, we calculate the economic cross-efficiency scores corresponding to the Farrell (cost) and the Nerlovian (profit) economic definitions introduced by Aparicio and Zofío (2019). In the first set of columns of Table 2, under the 'Technical (in)efficiency - Distance functions' heading, we report the results for the original Farrell input oriented model that radially measures technical efficiency for bank $k$ as in (1), but allowing for variable returns to scale (VRS) i.e., ITE $\left(X_{l}, Y_{l}\right)$ - see Ali and Seiford (1993) for the multiplier formulation of the program. The ranking of banks in the left column is precisely based on these values, which serves us as benchmark. As many as 12 banks (60\% of the observations) are technically efficient, exemplifying the poor discriminatory power of conventional DEA models in small samples and the need for cross-efficiency methods. ${ }^{9}$ The duality between the cost function and the (inverse) of the input distance function allows to introduce the bilateral cost cross-efficiency of firm / using the shadow prices of firm $k$, expression (5). Taking the arithmetic mean of all bilateral cross-inefficiencies yields the Farrell cross-efficiency measure (6), $F C E_{v}\left(X_{l}, Y_{l}\right)$, which is reported in the first (leftmost) column of the second group of results under the heading 'Economic cross (in)-efficiencies'. Here, it is interesting to remark that despite the use of cross-efficiency methods several banks are still tied in the first place with a cost crossefficiency score of one. Finally, the difference between the cost based economic crossefficiency measure and the input technical efficiency corresponds to the (average) of the allocative inefficiencies obtained for the $n$ shadow prices: $\frac{1}{n} \sum_{k=1}^{n} A E_{v}^{F}\left(X_{l}, Y_{l} ; V_{k}^{*}\right),(7)$. The values are reported once again in the first (left) column of the third group of results under the heading 'Allocative (in)efficiency'. Comparing technical and allocative efficiencies, we observe that the second component is a comparatively larger source of inefficiency.

The second set of results reported in Table 2 corresponds to the Nerlovian (profit) cross-efficiency. The values of the directional distance function under variable returns to scale, $\vec{D}_{v}\left(X_{k}, Y_{k} ; G^{x}, G^{y}\right)$ are calculated with the customary choice of directional vector corresponding to the observed input and output quantities, $\left(G^{x}, G^{y}\right)=\left(X_{1}, Y_{l}\right)$. We see that the same 12 bank are efficient and that the ranking for the inefficient observations is almost the same, except for banks \#18 and \#6, whose position is reversed. On this occasion, based on the duality between the profit function and the directional distance

9 The number of technically efficient banks reduces to 7 under constant returns to scale, the standard assumption in the cross-efficiency literature. 
function we can define the bilateral cross-inefficiency measure (12), and aggregating all bilateral cross-inefficiencies through the arithmetic mean yields the Nerlovian profit cross-inefficiency, $\mathrm{NCI}_{v}\left(X_{l}, Y_{l} ; G^{x}, G^{y}\right)$ in (13), which is reported in the second column of the second group of results. Contrary to the Farrell cost cross-efficiency, none of the banks are Nerlovian cross-efficient. As before, the difference between profit crossinefficiency and the technical efficiency score of the bank under evaluation (represented by the directional distance function), yields the average of allocative inefficiencies: $\frac{1}{n} \sum_{k=1}^{n} A I_{v}^{N}\left(X_{l}, Y_{l} ; \vec{V}_{k}^{*}, \vec{U}_{k}^{*} ; G^{x}, G^{y}\right)$ in (14). In this model, allocative inefficiency is almost the sole responsible of overall economic cross-inefficiency on average. 
Table 2. Economic cross-efficiency decompositions.

\begin{tabular}{|c|c|c|c|c|c|c|c|c|c|c|c|c|c|c|c|c|c|}
\hline \multirow[b]{2}{*}{ Ranking } & \multirow[b]{2}{*}{ Bank } & \multicolumn{6}{|c|}{ Technical (in)efficiency - Distance functions } & \multicolumn{5}{|c|}{ Economic cross-(in)efficiency } & \multicolumn{5}{|c|}{ Allocative (in)efficiency } \\
\hline & & $\begin{array}{l}I T E_{v} \\
(1)\end{array}$ & $\begin{array}{c}\vec{D}_{v}^{F} \\
(10)\end{array}$ & $\begin{array}{c}D_{c}^{G} \\
(16)\end{array}$ & $\begin{array}{c}D_{v}^{G} \\
\left(16^{\prime}\right)\end{array}$ & $\begin{array}{l}W A_{v} \\
(33)\end{array}$ & $\begin{array}{l}D_{\|\|_{q}} \\
(39)\end{array}$ & $\begin{array}{c}F C E_{v} \\
(6)\end{array}$ & $\begin{array}{l}N C l v \\
(13)\end{array}$ & $\begin{array}{c}P C E_{c} \\
(19)\end{array}$ & $\begin{array}{c}W A D D_{v} \\
(35)\end{array}$ & $\begin{array}{l}H C l v \\
(43)\end{array}$ & $\begin{array}{c}A E_{v}^{F} \\
(7)\end{array}$ & $\begin{array}{l}A l_{v}^{N} \\
(14)\end{array}$ & $\begin{array}{l}A E_{v}^{G} \\
(20)\end{array}$ & $\begin{array}{l}A I_{v}^{W} \\
(37)\end{array}$ & $\begin{array}{l}A I_{v}^{\|\|_{q}} \\
(44)\end{array}$ \\
\hline 1 & 1 & 1.000 & 0.000 & 1.000 & 1.000 & 0.000 & 0.000 & 0.749 & 0.659 & 0.526 & 13.700 & 0.196 & 0.749 & 0.659 & 0.526 & 13.700 & 0.196 \\
\hline 2 & 3 & 1.000 & 0.000 & 0.991 & 1.000 & 0.000 & 0.000 & 1.000 & 0.522 & 0.670 & 8.998 & 0.160 & 1.000 & 0.522 & 0.676 & 8.998 & 0.160 \\
\hline 3 & 4 & 1.000 & 0.000 & 1.000 & 1.000 & 0.000 & 0.000 & 1.000 & 0.333 & 0.772 & 2.000 & 0.097 & 1.000 & 0.333 & 0.772 & 2.000 & 0.097 \\
\hline 4 & 7 & 1.000 & 0.000 & 1.000 & 1.000 & 0.000 & 0.000 & 1.000 & 0.330 & 0.864 & 2.943 & 0.091 & 1.000 & 0.330 & 0.864 & 2.943 & 0.091 \\
\hline 5 & 8 & 1.000 & 0.000 & 0.798 & 1.000 & 0.000 & 0.000 & 0.736 & 1.119 & 0.345 & 18.180 & 0.230 & 0.736 & 1.119 & 0.432 & 18.180 & 0.230 \\
\hline 6 & 9 & 1.000 & 0.000 & 0.789 & 1.000 & 0.000 & 0.000 & 0.979 & 1.071 & 0.529 & 9.153 & 0.155 & 0.979 & 1.071 & 0.670 & 9.153 & 0.155 \\
\hline 7 & 10 & 1.000 & 0.000 & 0.289 & 1.000 & 19.648 & 0.000 & 0.694 & 2.498 & 0.176 & & 0.262 & 0.694 & 2.498 & 0.608 & 43.064 & 0.262 \\
\hline 8 & 12 & 1.000 & 0.000 & 1.000 & 1.000 & 0.000 & 0.000 & 1.000 & 0.502 & 0.791 & 4.024 & 0.125 & 1.000 & 0.502 & 0.791 & 4.024 & 0.125 \\
\hline 9 & 15 & 1.000 & 0.000 & 1.000 & 1.000 & 0.000 & 0.000 & 1.000 & 1.115 & 0.656 & 4.734 & 0.020 & 1.000 & 1.115 & 0.656 & 4.734 & 0.020 \\
\hline 10 & 17 & 1.000 & 0.000 & 1.000 & 1.000 & 0.000 & 0.000 & 1.000 & 0.932 & 0.625 & 12.500 & 0.173 & 1.000 & 0.932 & 0.625 & 12.500 & 0.173 \\
\hline 11 & 19 & 1.000 & 0.000 & 0.408 & 1.000 & 0.000 & 0.000 & 0.896 & 2.500 & 0.257 & 17.575 & 0.214 & 0.896 & 2.500 & 0.628 & 17.575 & 0.214 \\
\hline 12 & 20 & 1.000 & 0.000 & 1.000 & 1.000 & 0.000 & 0.000 & 0.916 & 0.582 & 0.649 & 0.040 & 0.134 & 0.916 & 0.582 & 0.649 & 8.040 & 0.134 \\
\hline 13 & 2 & 0.969 & 0.024 & 0.833 & 0.952 & 1.732 & 0.012 & 0.711 & 0.521 & 0.490 & 19.946 & 0.224 & 0.733 & 0.497 & 0.588 & 18.214 & 0.212 \\
\hline 14 & 5 & 0.927 & 0.043 & 0.899 & 0.918 & 2.556 & 0.018 & 0.796 & 0.596 & 0.617 & 8.016 & 0.181 & 0.859 & 0.553 & 0.686 & 5.460 & 0.163 \\
\hline 15 & 13 & 0.923 & 0.052 & 0.817 & 0.901 & 2.036 & 0.028 & 0.788 & 0.681 & 0.574 & 8.280 & 0.191 & 0.853 & 0.629 & 0.703 & 6.244 & 0.163 \\
\hline 16 & 18 & 0.896 & 0.104 & 0.473 & 0.802 & 9.951 & 0.060 & 0.767 & 2.026 & 0.303 & 25.732 & 0.224 & 0.856 & 1.922 & 0.639 & 15.781 & 0.164 \\
\hline 17 & 6 & 0.882 & 0.096 & 0.748 & 0.820 & 1.572 & 0.052 & 0.739 & 0.506 & 0.556 & 9.528 & 0.179 & 0.838 & 0.410 & 0.744 & 7.956 & 0.127 \\
\hline 18 & 16 & 0.813 & 0.146 & 0.639 & 0.738 & 3.459 & 0.071 & 0.665 & 0.914 & 0.392 & 12.140 & 0.253 & 0.818 & 0.768 & 0.613 & 8.681 & 0.182 \\
\hline 19 & 11 & 0.796 & 0.151 & 0.604 & 0.731 & 2.446 & 0.072 & 0.678 & 0.826 & 0.414 & 9.414 & 0.243 & 0.852 & 0.675 & 0.685 & 6.968 & 0.171 \\
\hline \multirow[t]{6}{*}{20} & 14 & 0.695 & 0.281 & 0.470 & 0.535 & 4.843 & 0.168 & 0.576 & 0.914 & 0.350 & 16.157 & 0.288 & 0.829 & 0.633 & 0.746 & 11.314 & 0.120 \\
\hline & Average & 0.945 & 0.045 & 0.788 & 0.920 & 2.412 & 0.024 & 0.835 & 0.957 & 0.528 & 13.689 & 0.182 & 0.880 & 0.912 & 0.665 & 11.276 & 0.158 \\
\hline & Median & 1.000 & 0.000 & 0.825 & 1.000 & 0.000 & 0.000 & 0.792 & 0.754 & 0.543 & 9.471 & 0.186 & 0.858 & 0.646 & 0.663 & 8.840 & 0.163 \\
\hline & Minimum & 0.695 & 0.000 & 0.289 & 0.535 & 0.000 & 0.000 & 0.576 & 0.330 & 0.176 & 2.000 & 0.020 & 0.694 & 0.330 & 0.432 & 2.000 & 0.020 \\
\hline & Maximum & 1.000 & 0.281 & 1.000 & 1.000 & 19.648 & 0.168 & 1.000 & 2.500 & 0.864 & 62.712 & 0.288 & 1.000 & 2.500 & 0.864 & 43.064 & 0.262 \\
\hline & Stand. Dev. & 0.088 & 0.075 & 0.232 & 0.130 & 4.736 & 0.043 & 0.142 & 0.649 & 0.186 & 13.038 & 0.066 & 0.103 & 0.654 & 0.095 & 9.003 & 0.054 \\
\hline
\end{tabular}

Source: Own elaboration. 
One wonders if the previously observed similarity in the technical efficiency rankings based on the input and directional distance functions extends to their respective economic cross-(in)efficiencies. As shown in Table 3, the Spearman rank correlation between these results turns out to be rather low: $\rho\left(F C E_{v}\left(X_{l}, Y_{l}\right), N C I_{v}\left(X_{l}, Y_{i} ; G^{x}, G^{y}\right)\right)$ $=0.3131$, not being statistically significant at the usual levels of confidence. The low correlation would be expected, as this simply shows how different rankings can be depending on the cross-(in)efficiency models that are compared. In particular whether (i) they correspond to a multiplicative or additive definition of economic efficiency, and whether (ii) they are based on a partial dimension of the production process and corresponding economic objective (e.g., input orientation and cost minimization), versus a complete characterization that takes into account both inputs and outputs and a maximizing profit behavior. In this case the Farrell and Nerlovian economic crossefficiency models differ in both aspects, and therefore a weak correlation could be anticipated.

Table 3. Rank correlations of cross-(in)efficiencies. Spearman coefficients.

\begin{tabular}{c|c|c|c|c|c} 
& $F C E_{v}(6)$ & $N C I_{v}(13)$ & $P C E_{c}(19)$ & $W A D D_{v}(35)$ & $H C I_{v}(43)$ \\
\hline$F C E_{v}$ & 1.0000 & & & & \\
\hline$N C I_{v}$ & 0.3133 & 1.0000 & & & \\
\hline$P C E_{c}$ & $0.7909^{*}$ & $0.7499^{*}$ & 1.0000 & & \\
\hline$W A D D_{v}$ & $0.6713^{*}$ & $0.6431^{*}$ & $0.8932^{*}$ & 1.0000 & \\
\hline$H C I_{v}$ & $0.9170^{*}$ & $0.5004^{*}$ & $0.8853^{*}$ & $0.8101^{*}$ & 1.0000 \\
\hline
\end{tabular}

Notes: Correlations calculated once the (additive) economic cross-inefficiency scores are multiplied by -1 , so the rankings are based on the same numerical interpretation, i.e., the greater the value, the higher the position in the ranking; ${ }^{*} p$-value $<0.01$.

Source: Own elaboration

\subsection{New measures of economic cross-(in)efficiency}

Subsequently, in the third column of the first group of results in Table 2, we find the generalized distance function, $D_{c}^{G}\left(X_{k}, Y_{k} ; \gamma\right)$ in (16), representing the technical part of the profitability cross-efficiency model, $P C E_{c}\left(X_{l}, Y_{l} ; \gamma\right)$ in (19). To obtain these results we have chosen $\gamma=0.5$, a value that weights equally inputs and outputs when projecting the banks to the production frontier and therefore is neutral. Both the technical and economic cross-efficiency scores corresponding to this multiplicative approach are significantly lower than those reported for the Farrell cost cross-efficiency model. The 
reason is that profitability cross-efficiency is measured under the constant returns to scale (CRS) characterization of the production technology, while the rest of crossefficiencies allow for VRS. Thus, the efficiency scores are smaller in the profitability model. This difference can be attributed to scale inefficiencies. For this reason we present in the fourth column the directional distance function under variables returns to scale, $D_{v}^{G}\left(X_{k}, Y_{k} ; \gamma\right)$. This allows calculation of the magnitude of the scale efficiency as $S E^{G}\left(X_{k}, X_{k} ; \gamma\right)=D_{c}^{G}\left(X_{k}, X_{k} ; \gamma\right) / D_{v}^{G}\left(X_{k}, X_{k} ; \gamma\right)$. On average, scale inefficiency is 0.8565 , which means that if banks were to produce at one of the most productive scale sizes (Banker et al., 1984), they could yield about $15 \%$ more quantity of outputs with a similar reduction in the quantity of inputs employed. Also, looking at the subset of 12 banks that are efficient under VRS, as many as 5 are scale inefficient (\#3, \#8, \#9, \#10 and \#19). Moving on to profitability cross-efficiency, $P C E_{c}\left(X_{l}, Y_{l} ; \gamma\right)$ is reported in the third column of the second group of results. Despite the fact that the profit crossefficiency takes into account both the input and output dimensions of the production process, its ranking of banks correlates positively with that corresponding to the Farrell cost definition, showing the compatibility of these two multiplicative measures in the current application: $\rho\left(F C E_{v}\left(X_{l}, Y_{l}\right), P C E_{c}\left(X_{l}, Y_{i} ; \gamma\right)\right)=0.7909$ statistically significant at the $1 \%$ level. Completing the results for this measure, the ratio of the profitability crossefficiency measure to the generalized distance function corresponds to the allocative efficiency factor, $\left(\prod_{j=1}^{n} A E_{c}^{G}\left(X_{k}, Y_{k} ; V_{k}^{*}, U_{k}^{*} ; \gamma\right)\right)^{1 / n}$ in (20), presented in the third column of the third group of results. Looking at the average of the technical and allocative components, the weight of the latter term is relatively larger than the former (as in the multiplicative Farrell cost model).

We now focus on the last two alternative definitions of profit cross-inefficiency based on the duality between the profit function and either the weighted additive distance function and the Hölder distance functions, respectively. The results corresponding to the former, WA $\left(X_{k}, Y_{k} ; A_{k}, B_{k}\right)$ in (33), are shown in the fifth column of the first group of results. Because of its different normalization constraint, its values are significantly larger than those observed for the-also additive-directional distance function $\vec{D}_{v}\left(X_{k}, Y_{k} ; G^{x}, G^{y}\right)$, with bank \#10 performing rather poorly. The values of the profit crossinefficiency corresponding to this model, $W C_{v}\left(X_{l}, Y_{l} ; A_{l}, B_{l}\right)$ in (35), can be found in the fourth column of the second group of results, while its associated allocative inefficiency 
in the same column of the third group of results, i.e., $\frac{1}{n} \sum_{k=1}^{n} A l_{V}^{w}\left(X_{l}, Y_{l} ; V_{k}^{*}, U_{k}^{*} ; A_{l}, B_{l}\right)$ in (37)

As for the Hölder distance function, $D_{\|\|_{q}}\left(X_{k}, Y_{k}\right)$ in (39), underlying the last definition of profit cross-inefficiency, we choose as reference the infinitum norm, $\ell_{\infty}$ - see Aparicio et al. (2016). This makes this function equal to the directional distance function when the directional vector is unit-valued, i.e., $\left(G^{x}, G^{y}\right)=(1,1)$. For that reason, the results can be readily compared to those previously reported for the directional distance function: $\vec{D}_{v}\left(X_{k}, Y_{k} ; G^{x}, G^{y}\right)$ with $\left(G^{x}, G^{y}\right)=\left(X_{l}, Y_{l}\right)$. This also extends to the comparison between the Hölder and Nerlovian profit cross-inefficiencies. The results for the Hölder distance function are reported in the last (rightmost) column of the first group of results, with the 12 technically efficient banks exhibiting, once again, zero-valued scores. Finally, the Hölder cross-inefficiency scores, $\mathrm{HCl}_{v}\left(X_{l}, Y_{l}\right)$ in (43), and its corresponding allocative inefficiencies, $\frac{1}{n} \sum_{k=1}^{n} A I_{V}^{l \|_{q}}\left(X_{l}, Y_{i} ; V_{k}^{*}, U_{k}^{*}\right)$ in (44), are shown in the last (rightmost) columns of the second and third group of results, respectively. As in the Nerlovian profit model, the allocative component is the main source of inefficiency.

The compatibility between rankings resulting from the same economic efficiency definition (i.e., profit) are rather high, with the Spearman correlations in the range set by $\rho\left(\mathrm{NCl}_{v}\left(X_{l}, Y_{l} ; G^{X}, G^{y}\right), \mathrm{HCl}_{v}\left(X_{l}, Y_{l}\right)\right)=0.5004$ and $\rho\left(W A_{v}(X, Y ; A, B), \mathrm{HCl}_{v}\left(X_{l}, Y_{l}\right)\right)=$ 0.8101 -both statistically significant as identified in Table 3. Scanning through all coefficients, it is the ranking based on the profitability cross-inefficiency the one with the higher correlations with either its multiplicative or additive alternatives. This is a relevant result since the profitability ranking is based on constant returns to scale while its alternatives are created under the assumption of variable returns. This suggests that the rankings are not significantly affected by the existence of scale inefficiencies. On the other side, it seems that it is the ranking based on the Nerlovian profit cross-inefficiency the one that correlates less with any of its alternatives. Also, and rather surprisingly, the rankings from the multiplicative, partially oriented, Farrell (cost) cross-efficiency, and the additive Hölder (profit) cross-inefficiency are those presenting the highest (and significant) correlation: $\rho\left(F C E_{v}\left(X_{l}, Y_{l}\right), \mathrm{HCl}_{v}\left(X_{l}, Y_{l}\right)\right)=0.9170$. The relative values for the technical and allocative inefficiencies follow the exact same pattern that in the previous Nerlovian and weighted additive models. 


\section{Summary and conclusions}

This study extends the existing definitions of economic cross-(in)efficiency proposed by Aparicio and Zofío (2019) by introducing a new set of multiplicative and additive measures that can be obtained from the duality relationship between alternative representations of economic behavior and their distance function technological counterparts. Economic cross-(in)efficiency measures the performance of firms in terms of a set of reference prices that could correspond to either market prices, shadow prices or any other imputed prices. When market prices are available, it can be shown that for homothetic technologies, the process of benchmarking corresponds to the usual economic efficiency definitions, e.g., à la Farrell regarding cost efficiency or à la Nerlove in the case of profit inefficiency. However, mirroring cross-inefficiency methods, it is possible to adapt this framework by considering the complete set of shadow prices that are obtained when evaluating the technical efficiency of all firms within the sample. This overall economic measure can be interpreted as the capability of firms to behave optimally by reaching minimum cost or maximum profit for a wide range of prices. The new methodology is particularly relevant in studies where market prices are not readily available because of the institutional framework (e.g., public services such as education, health, safety, etc.), but yet a robust ranking of observations based on their performance is demanded by decision makers and stakeholders.

The combination of the economic and cross-efficiency literatures solves some of the weaknesses of the standard approaches based on DEA for ranking observations, as when there is a large set of them that are technically efficient, resulting in ties for the first place. Cross-efficiency methods were introduced in part to solve that drawback, yet they have been only applied under the assumption of constant returns to scale because of the negative scores that may be obtained when the technology is characterized by variable returns to scale. The economic cross-(in)efficiency methodology solves this problem in a natural way, without proposing ad-hoc methods such as those based on data translations (Lim and Zhu, 2015). Also, recent critics raised against cross-efficiency methods regarding the (unrealistic) interpretation of the DEA multipliers as sensible shadow prices (Førsund, 2018a, 2018b), can now be addressed under the new paradigm, since they can be understood as actual realizations of possible market prices.

To be consistent in the definition of economic cross-(in)efficiency, a duality relationship between a supporting economic function and its corresponding distance function is required. This allows the decomposition in a subsequent stage of economic cross-efficiencies into technical efficiency (the actual value of the distance function) and 
a residual defined as either the arithmetic or geometric mean of the allocative (in)efficiency residuals. Following this scheme, we introduce two new multiplicative definitions of economic cross-efficiency. The first one relates the profitability function, defined as the ratio of revenue to costs (Georgescu-Roegen, 1951), and the generalized distance function (Chavas and Cox, 1999). The second one can be seen as a particular case of the former that relates the revenue function and the output distance function (Shephard, 1953)_just as the Farrell cost cross-efficiency approach. We also present two alternative additive definitions of economic cross-inefficiencies based in the duality between the profit function and either the weighted additive distance function (Cooper et al., 2011), or the Hölder distance function (Briec and Lesourd, 1999). In passing we note that these two distance functions are particular cases of the loss function introduced by Aparicio et al. (2016), which could be eventually used to develop the most general model of economic cross-inefficiency. All these and previous models of economic crossefficiency correspond to a cross-sectional evaluation of performance, but they can be extended to panel data. In this case the change on cost efficiency over time can be combined with our proposed reinterpretation of cross-efficiency methods to yield, thereby obtained the counterpart to the so-called cost-Malmquist (Maniadakis and Thanassoulis, 2004) and profit-Luenberger indicators (Juo et al., 2015). Following the same procedure these variations can be decomposed into quantity productivity indices or indicators, and a residual capturing the role played by changes in prices (i.e., allocative efficiency change) and technological change.

We show also that the new models can be implemented empirically using DEA techniques. For this we rely on a database of financial institutions previously used in the cross-efficiency literature. The results show the suitability of adopting the economic cross-(in)efficiency approach to rank observations according to their productive performance, and its decomposition into its technical and allocative sources. For this particular application, we find that results are in general compatible across models (particularly for the relative weight of technical and allocative (in)efficiencies), resulting in rather high Spearman correlations. This result is also observed for models that are quite dissimilar in principle; i.e., those based on a partial orientation such as the Farrell cost cross-efficiency and the input distance function, and a complete characterization of the production process based on the profit function and the Hölder distance function. Nevertheless, the correlation between the former and the Nerlovian economic crossefficiency is in turn the lowest across all models. This shows that, as with any efficiency and productivity study, the choice of the appropriate reference model is critical when assessing performance. 
We conclude suggesting some paths for further research related to both the economic efficiency and the cross-efficiency literature that could be brought to the new models of economic cross-efficiency. Regarding the former, it is well known that if technologies are non-homothetic, the standard decompositions of economic efficiency fail to correctly characterize technical and allocative inefficiency. Within the non-DEA approach Aparicio et al. (2015) show that, for non-homothetic technologies, the radial contractions (expansions) of the input (output) vectors resulting in efficiency gains do not maintain allocative (in)efficiency constant along the firm's projection to the production frontier (isoquants). This implies that they cannot be solely interpreted as technical efficiency reductions. From the perspective of, for example, the Farrell cost efficiency decomposition in this study, this result invalidates the residual nature of allocative efficiency, and justifies the use of flexible distance functions (i.e., directional, weighted additive, Hölder, etc.) with a choice of directional vector capable of keeping allocative efficiency constant along the projections. As for cross-efficiency, it is well-known that there exist alternative optima for the DEA models, which may result in different crossefficiency scores. To overcome this situation, weights restrictions could be employed as suggested by Ramón et al. (2010). Yet another possibility is the adoption of secondary goals such as the so-called benevolent and aggressive approaches proposed by Sexton et al. (1986) and Doyle and Green (1994). See also Liang et al. (2008a) and Lim (2012) for further refinements. It is also possible to adopt a game cross efficiency approach as in Liang et al. (2008b). All these are relevant qualifications and natural extensions that would result in the consolidation and improvement of cross-efficiency methods, making their diffusion to wider audiences more likely.

\section{Acknowledgements}

J. Aparicio and J. L. Zofío thank the financial support from the Spanish Ministry for Economy and Competitiveness (Ministerio de Economía, Industria y Competitividad), the State Research Agency (Agencia Estatal de Investigación) and the European Regional Development Fund (Fondo Europeo de Desarrollo Regional) under grant MTM201679765-P (AEI/FEDER, UE). 


\section{References}

Aczél, J. and Roberts, F. S. (1989) On the possible merging functions, Mathematical Social Sciences 17: 205-243.

Akbarian, D. (2015) Ranking all DEA-efficient DMUs based on cross efficiency and analytic hierarchy process methods. Journal of Optimization, Article ID 594727, 10 pages.

Ali, A. I. and Seiford, L. M. (1993) The mathematical programming approach to efficiency analysis. In: Fried H.O., Lovell C.A.K. and Schmidt S.S. (eds). The Measurement of Productive Efficiency: Techniques and Applications. Oxford University Press, New York, Oxford, 120-159.

Amirteimoori, A. and Kordrostami, S. (2005) Efficient surfaces and an efficiency index in DEA: a constant returns to scale. Applied Mathematics and Computation, 163(2), 683-691.

Aparicio, J., Pastor, J.T., Sainz-Pardo, J.L. and Vidal, F. (2017a) Estimating and decomposing overall inefficiency by determining the least distance to the strongly efficient frontier in data envelopment analysis. Operational Research, 1-24. doi.org/10.1007/s12351-017-0339-0.

Aparicio, J., Borras, F., Ortiz, L., Pastor, J.T. and Vidal, F. (2017b) Luenberger-type indicators based on the weighted additive distance function. Annals of Operations Research, 1-19. doi.org/10.1007/s10479-017-2620-2.

Aparicio, J., Borras, J., Pastor, J.T. and Zofío, J.L. (2016) Loss Distance Functions and Profit Function: General Duality Results, in Aparicio, J. Knox Lovell, C.A. and Pastor, J.T. (edts.) Advances in Efficiency and Productivity, Springer: NY, 76-91.

Aparicio, J., Pastor, J. T. and Zofio, J. L. (2015) How to properly decompose economic efficiency using technical and allocative criteria with non-homothetic DEA technologies. European Journal of Operational Research, 240(3), 882-891.

Aparicio, J. and Zofío, J.L. (2019) Economic cross-efficiency: theory and DEA methods. ERIM Report Series Research in Management, No. ERS-2019-001-LIS. Erasmus Research Institute of Management (ERIM). Erasmus University Rotterdam, The Netherlands. http://hdl.handle.net/1765/115479.

Balk, B.M., de Koster, M.B.M., Kaps, C. and Zofío, J.L. (2017) An evaluation of crossefficiency methods, applied to measuring warehouse performance. ERIM Report Series Research in Management No. ERS-2017-015-LIS, Erasmus Research 
Institute of Management (ERIM), Erasmus University Rotterdam, The Netherlands. http://hdl.handle.net/1765/103185.

Balk, B.M. (2018) Profit-Oriented Productivity Change: A Comment. Omega 78: 176-178.

Banker, R.D., Charnes, A. and Cooper, W.W. (1984) Some models for estimating technical and scale inefficiencies in data envelopment analysis. Management Science 30(9): 1078-1092.

Briec, W. (1998) Hölder distance function and measurement of technical efficiency. Journal of Productivity Analysis, 11(2), 111-131.

Briec, W. and Lesourd, J.B. (1999) Metric distance function and profit: some duality results. Journal of Optimization Theory and Applications 101(1): 15-33.

Chambers, R.G., Chung, Y. and Färe, R. (1998) Profit, directional distance functions and Nerlovian efficiency. Journal of Optimization Theory and Applications 98 (2): 351364.

Charnes, A., Cooper, W.W. and Rhodes, E. (1978) Measuring the efficiency of decision making units. European Journal of Operational Research 2(6): 429-444.

Chavas J-P. and Cox, T. M. (1999) A generalized distance function and the analysis of production efficiency. Southern Economic Journal 66(2): 295-318.

Cooper, W.W., Pastor, J.T., Aparicio, J. and Borras, F. (2011) Decomposing profit inefficiency in DEA through the weighted additive model. European Journal of Operational Research 212(2): 411-416.

Doyle, J. R. and Green, R. H. (1994) Efficiency and cross-efficiency in DEA: Derivations, meanings, and uses, Journal of the Operational Research Society, 45: 567-578.

Färe, R., Grosskopf, S. and Zaim, O. (2002) Hyperbolic efficiency and return to the dollar. European Journal of Operational Research, 136(3), 671-679.

Färe, R. and Primont, D. (1995) Multi-Output Production and Duality: Theory and Applications, Kluwer Academic.

Farrell, M.J. (1957) The measurement of productive efficiency. Journal of the Royal Statistical Society, Series A, General, 120: 253-281.

Førsund, F.R. (2018a) Economic interpretations of DEA. Socio-Economic Planning Sciences, 61: 9-15.

Førsund, F.R. (2018b) Cross-efficiency: A critique. Data Envelopment Analysis Journal, 4: 1-25. 
Georgescu-Roegen, N. (1951) The aggregate linear production function and its application to von Newman's economic model. In: Koopmans T (ed.) Activity analysis of production and allocation. Wiley, New York, 98-115.

Juo, J. C., Fu, T. T., Yu, M. M. and Lin, Y. H. (2015) Profit-oriented productivity change. Omega, 57, 176-187.

Liang, L., W.J, Cook, W.D. and Zhu. J. (2008a) Alternative secondary goals in DEA cross-efficiency evaluation. International Journal of Production Economics, 113(2): 1025-1030.

Liang, L., Wu, J., Cook, W.D. and Zhu, J. (2008b) The DEA game cross-efficiency model and its Nash equilibrium. Operations Research, 56(5):1278-1288

Lim, S. (2012) Minimax and maximin formulations of cross-efficiency in DEA. Computers and Industrial Engineering, 62(3):726-731

Lim, S. and Zhu, J. (2015) DEA cross-efficiency evaluation under variable returns to scale. Journal of the Operational Research Society, 66(3), 476-487.

Luenberger, D.G. (1992) New optimality principles for economic efficiency and equilibrium. Journal of optimization theory and applications, 75(2), 221-264.

Maniadakis, N. and Thanassoulis, E. (2004) A cost Malmquist productivity index. European Journal of Operational Research, 154(2), 396-409.

Nerlove, M. (1965) Estimation and identification of Cobb-Douglas production functions. Rand McNally.

Olesen, O.B. (2018) Cross efficiency analysis and extended facets. Data Envelopment Analysis Journal, 4: 27-64.

Ramón, N., Ruiz, J.L. and Sirvent, I. (2010) On the choice of weights profiles in crossefficiency evaluations. European Journal of Operations Research, 207: 1564-1572.

Ruiz, J.L. (2013) Cross-efficiency evaluation with directional distance functions. European Journal of Operational Research, 228(1): 181-189.

Sexton, T. R., Silkman, R. H. and Hogan, A. J. (1986) Data envelopment analysis: Critique and extensions, in: Silkman, R. H. (edt.) Measuring Efficiency: An Assessment of Data Envelopment Analysis, New Directions for Program Evaluation 32, Jossey-Bass: San Francisco/London, 73-105.

Shephard, R.W. (1953) Cost and Production Functions. Princeton Univ. Press.: Princeton, NJ. 
Wu, J., Liang, L. and Chen, Y. (2009) DEA game cross-efficiency approach to Olympic rankings. Omega, 37(4), 909-918.

Zofío, J. L. and Prieto, A. M. (2006) Return to dollar, generalized distance function and the Fisher productivity index. Spanish Economic Review, 8(2), 113-138. 